\title{
¿Climatology of Low-Level Jets and Their Impact on Rainfall over Southern China during the Early-Summer Rainy Season
}

\author{
Yu DU AND GUIXING CHEN \\ School of Atmospheric Sciences, and Guangdong Province Key Laboratory for Climate Change and Natural Disaster Studies, \\ Sun Yat-sen University, Guangzhou, and Southern Marine Science and Engineering Guangdong Laboratory (Zhuhai), \\ Zhuhai, China
}

(Manuscript received 25 April 2019, in final form 20 August 2019)

\begin{abstract}
Low-level jets (LLJs) are a key factor regulating the early-summer rainfall over southern China. Their detailed activities and impact are examined using 21-yr ERA5 and TRMM rainfall data. The LLJs typically consist of boundary layer jets (BLJs) and synoptic-system-related LLJs (SLLJs). The BLJ is usually characterized by a southerly wind maximum at $950 \mathrm{hPa}$ over the northern area of South China Sea, whereas the SLLJ features a southwesterly wind maximum at $850-700 \mathrm{hPa}$ located more north on land. Meanwhile, the BLJ (SLLJ) has a maximum occurrence in April-June (May-July) and at late night (in the early morning), indicating the differences in seasonal and diurnal variations. The two types of LLJs are found to influence the rainfall distribution via terrain effects, synoptic disturbances, and moisture transport. During the BLJ events, rainfall is mainly confined to the south side of the Nanling and Wuyi Mountains and Yun-Gui Plateau (south region), whereas during the SLLJ events rainfall occurs both in the coastal region and to the north of the mountains (north region). The difference is caused by the southerly BLJ that induces strong orographic lifting on the windward side of the mountains, while the elevated SLLJ can pass over the mountains driving an additional upward motion more north. Active synoptic disturbances accompanied by SLLJs are also favorable for the rainfall in the north region. The moisture transportation by LLJs is another important factor regulating rainfall distribution. Rainfall in the south (north) region is mainly attributed to the net moisture flux in the boundary layer (more elevated layers) due to the BLJ (SLLJ).
\end{abstract}

\section{Introduction}

Low-level jets (LLJs), defined as the wind maximum in the lowest few kilometers of the atmosphere, occur globally as an important atmospheric phenomenon (Stensrud 1996; Rife et al. 2010). Since LLJs are closely related to precipitation, wind energy, and pollution transportation, they have been widely studied (e.g., Bonner 1968; Chen and Yu 1988; Monaghan et al. 2010; Liu et al. 2014; Rasmussen and Houze 2016). In fact, LLJs can be classified into two types: 1) boundary layer jets (BLJs), which occur below $1 \mathrm{~km}$ and are always associated with boundary layer processes; and 2) synopticweather-related LLJs (SLLJs), which occur in the layers higher than the BLJ (1-4 km of the free troposphere)

๑ Denotes content that is immediately available upon publication as open access.

Corresponding author: Yu Du, duyu7@mail.sysu.edu.cn with larger vertical extent and are more related to synoptic or subsynoptic systems (Chen et al. 1994; Du et al. 2012, 2014). It is noted that BLJs can also be influenced by large-scale circulation or synoptic or subsynoptic systems (Du and Chen 2018). Improved understanding of the features and impacts of two types of LLJs should lead to improved weather and climate predictions.

Among LLJs around the world, LLJs over the U.S. Great Plains (GPLLJs) have been well documented as to their characteristics and formation mechanisms in previous studies (Whiteman et al. 1997; Banta et al. 2002; Jiang et al. 2007; Ting and Wang 2006; Shapiro and Fedorovich 2009). The GPLLJs mainly belong to the classical BLJs featuring a pronounced diurnal cycle with a maximum at night. BLJs are found to form and develop by inertial oscillation (the Blackadar mechanism; Blackadar 1957) and baroclinicity over a sloping terrain (the Holton mechanism; Holton 1967) or their combination (Du and Rotunno 2014; Shapiro et al. 2016). On the other hand, some GPLLJs form in association with 
synoptic-scale forcing and extend above the boundary layer, which are regarded as SLLJs. Uccellini and Johnson (1979) studied a case of a SLLJ that develops in the lower branch of an ageostrophic circulation related to the exit region of an upper-level jet. Uccellini (1980) found more cases of SLLJ over the Great Plains. These previous studies indicated that the two types of LLJs show different formation processes and characteristics. The climatological studies can help understand the relationship between those LLJs and their key factors such as background circulation and terrains.

In recent years, the studies of LLJs in China have been increasing through observation, numerical simulation, climatological, and theoretical studies (Du et al. 2012, 2014, 2015a,b; He et al. 2016; Zhang et al. 2018; Li et al. 2018; Shu et al. 2018; Miao et al. 2018). BLJs frequently occur over or next to high terrain and coastal areas, while SLLJs are often associated with the cold vortex over northeastern China or the mei-yu front over southern China (Du et al. 2014). Like their counterparts in the Great Plains, the two types of LLJs exhibit different characteristics and formation mechanisms in China. In particular, the BLJs have an obvious diurnal cycle with a maximum at night, whereas most SLLJs do not show a significant diurnal cycle, but the SLLJs over southern China peak in the morning. The formation of the BLJs in China may be attributed to the combined Blackadar and Holton mechanisms, whereas the synoptic weather disturbances account for the formation of SLLJs (Chen and Yu 1988; Tao and Chen 1987; Du et al. 2015b; Fu et al. 2019; Xue et al. 2018). Du et al. (2014) found that both BLJs and SLLJs are apparently active over southern China. However, their differences in detailed climatological characteristics, including their interannual, seasonal, and diurnal variations, are not well known.

It has been widely recognized that LLJs provide favorable thermodynamic conditions by transporting warm moist air and cause convergence at their termini (e.g., Astling et al. 1985; Tuttle and Davis 2006; Trier and Parsons 1993; Trier and Parsons 1993; Higgins et al. 1997; Trier et al. 2006; Chen et al. 2017). They are thus observed to greatly affect the horizontal distribution of rainfall. Higgins et al. (1997) documented that the distribution of observed nighttime rainfall during LLJ events over the U.S. Great Plains is fundamentally different compared to nonjet events. Cook and Vizy (2010) also found that the strong Caribbean LLJ leads to an anomalous northward moisture transport and thus results in rainfall increases over Louisiana and Texas. Over southern China, both BLJs and SLLJs are active, but their differences of impact on rainfall are still not clear. In a case study, Du and Chen (2018) found that the SLLJ and BLJ are closely related to the frontal heavy rainfall and the warm-sector heavy rainfall, respectively. However, the different impacts of BLJs and SLLJs on precipitation need to be further studied in a climatological manner.

In the present study, using long-term reanalysis and satellite rainfall data we attempt to investigate the detailed climatology of the two types of LLJs over southern China and their impact on precipitation. Section 2 briefly introduces the data and statistical method. In section 3, we present the climatological characteristics of BLJs and SLLJs including their horizontal and vertical structures and temporal variations. The relationship between rainfall patterns and the BLJ or SLLJ is described in section 4. Section 5 discusses the possible impact mechanisms of LLJs on rainfall considering their related terrain effect, synoptic forcing, and moisture transportation. We further discuss some relevant seasonal variation regarding the impact of LLJs on rainfall in section 6. Finally, section 7 summarizes our results.

\section{Data and methodology}

\section{a. Data}

The multisatellite merged rainfall estimates from the Tropical Rainfall Measuring Mission (TRMM 3B42 v7; Huffman et al. 2007) are utilized to study the distribution of rainfall over both land and ocean. They are derived by microwave data and geostationary infrared data and have a temporal resolution of $3 \mathrm{~h}$ and a horizontal resolution of $0.25^{\circ}$. The TRMM data exhibit good performance in rainfall estimates over the regions with complex terrain and have been widely used (Zhou et al. 2008; Shen et al. 2010; Chen et al. 2018). We also conduct similar analysis using the Climate Prediction Center morphing technique rainfall dataset (CMORPH), which is generally consistent with TRMM.

To analyze LLJs' activities and related atmospheric processes, we use the latest ECMWF atmospheric reanalysis ERA5 (https://cds.climate.copernicus.eu/ cdsapp\#!/home) with a horizontal resolution of $0.25^{\circ} \times$ $0.25^{\circ}$ and a time interval of $1 \mathrm{~h}$ (data at 3-h intervals are chosen for consistency in temporal resolution with TRMM in the present study). ERA5 is the fifth generation of ECMWF atmospheric reanalyses of the global climate followed by ERA-Interim. We also checked out other datasets like ERA-Interim, which shows similar results but with lower resolution. Chen et al. (2014b) documented that the ERA-Interim has a small mean bias and root-mean-square error over southern China through comparing with sounding data. The period used in the present study of TRMM rainfall data 
and ERA5 covers from 1998 to 2018, which is their coinciding time.

\section{b. Criteria for identifying $L L J S$}

Following Whiteman et al. (1997) and Du et al. (2014), the criteria used to identify the existence of a LLJ are that 1) the maximum wind speed is more than $10 \mathrm{~m} \mathrm{~s}^{-1}$ below $700 \mathrm{hPa}$, and 2) below $600 \mathrm{hPa}$ the wind speed must decrease by at least $3 \mathrm{~m} \mathrm{~s}^{-1}$ from the height of the wind maximum to the wind minimum above that. We further classify the LLJs into BLJs where the level of maximum wind is in the lowest layer of $100 \mathrm{hPa}$ above the surface, and SLLJs where the level of maximum wind is above the lowest layer of $100 \mathrm{hPa}$.

Using 3-hourly ERA5 data, we define BLJ events over southern China or the northern South China Sea (SCS) if more than $20 \%$ of the grid points in the blue box in Fig. 1 satisfy the BLJ criteria and they are southerlies. Tu et al. (2019) used similar criteria to define BLJ events located to the upstream of Taiwan. Considering that the horizontal scale of the SLLJ is typically larger than that of the BLJ (Du and Chen 2018), we adopted a similar method to define the SLLJs as the BLJs, but more than $25 \%$ of the grid points in the blue box in Fig. 1 satisfy the SLLJ criteria and they are southwesterlies. It is noted that the region we choose is based on the LLJ occurrences and their influence area on rainfall (Du et al. 2014; Du and Chen 2018, 2019). Sometimes, BLJ and SLLJ events coexist and are regarded as double LLJ events (Du and Chen 2018, 2019). To avoid the mutual influence between BLJ and SLLJ events, we further define pure BLJ and SLLJ events when double LLJ events are excluded from BLJ and SLLJ events, respectively. To study the diurnal cycle, we further define BLJ (SLLJ) days as when at least one BLJ (SLLJ) event occurs in a day.

\section{c. Moisture fluxes and vapor transportation}

To illustrate horizontal moisture transportation in association with BLJs or SLLJs, the moisture fluxes $\left(\mathrm{kg} \mathrm{m}^{-2} \mathrm{~s}^{-1}\right)$ are calculated according to

$$
Q=\rho q V,
$$

where $\rho, q$, and $V$ are air density, water vapor mixing ratio, and wind velocity perpendicular into the given boundary, respectively. The plane integration of the moisture fluxes from $x_{1}$ and $x_{2}\left(\mathrm{~kg} \mathrm{~m}^{-1} \mathrm{~s}^{-1}\right)$ is calculated as

$$
\overline{Q_{x_{1} x_{2}}}=\int_{x_{1}}^{x_{2}} \rho q V d x
$$

The integration is over the length of the boundary from $x_{1}$ and $x_{2}$. The analysis of moisture fluxes has been

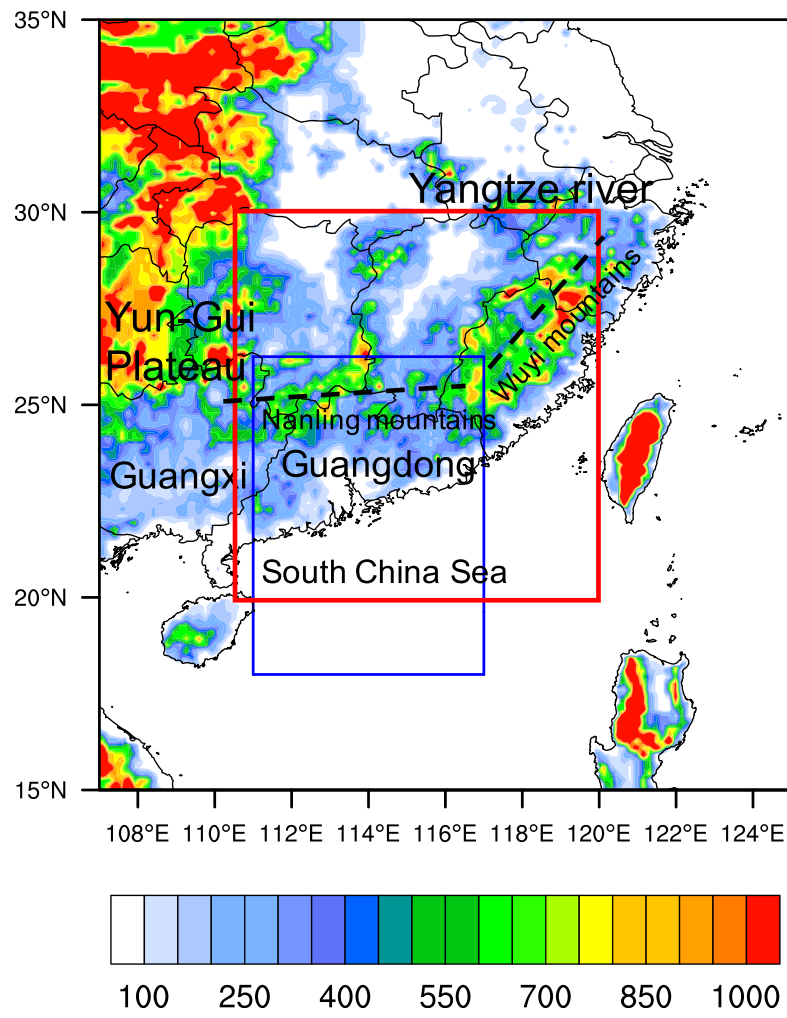

FIG. 1. Distribution of terrain height (shading; $m$ ). The blue and red boxes are the regions selected for the LLJ event definition and calculation of rainfall, respectively. The black dashed lines indicate the location and orientation of the Nanling and Wuyi Mountains.

widely used in the previous study of heavy rainfall and the diurnal cycle (Xue et al. 2018; Zhang et al. 2019).

\section{Characteristics of BLJ and SLLJ}

\section{a. Seasonal and interannual variation}

The occurrence frequencies of both BLJ and SLLJ events exhibit pronounced seasonal variation (Fig. 2a). The BLJ events frequently occur in April-July, whereas the SLLJ events often occur in May-July. If double LLJ events are excluded, the difference of seasonal peaks (April vs June) becomes more significant between pure BLJ and SLLJ events. Such differences might be attributed to the northward movement of monsoon. The active region of SLLJs is typically more north than that of BLJs, causing the later seasonal peak for the SLLJ events. As shown in Fig. 2a, rainfall in southern China reaches its annual peak during the early-summer rainy season (May-June; Li et al. 2018) when the mei-yu front occurs frequently over southern China. The secondary peak of rainfall occurs in July-September, which is the post-summer rainy season, mainly influenced by tropical 


\section{(a)}

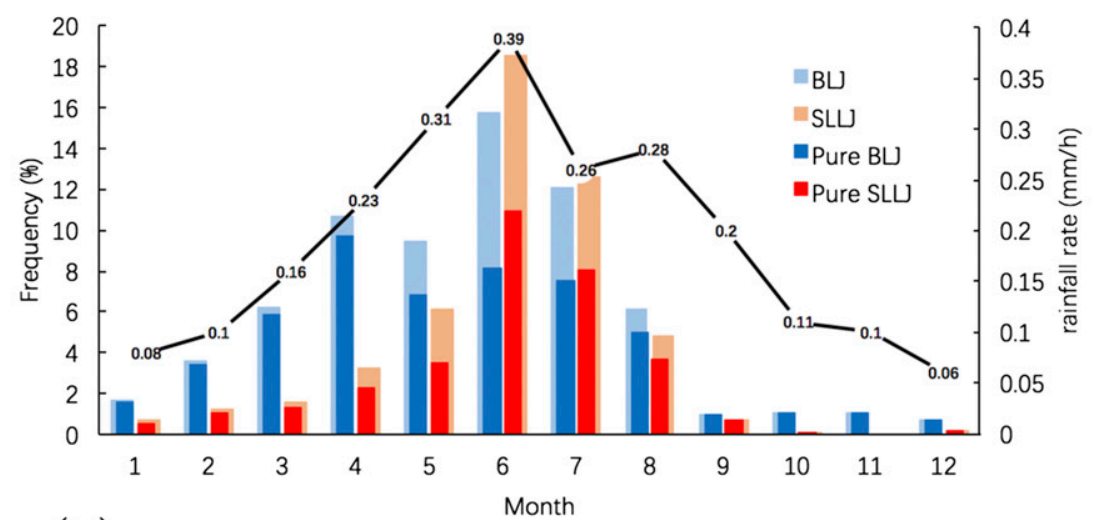

(b)
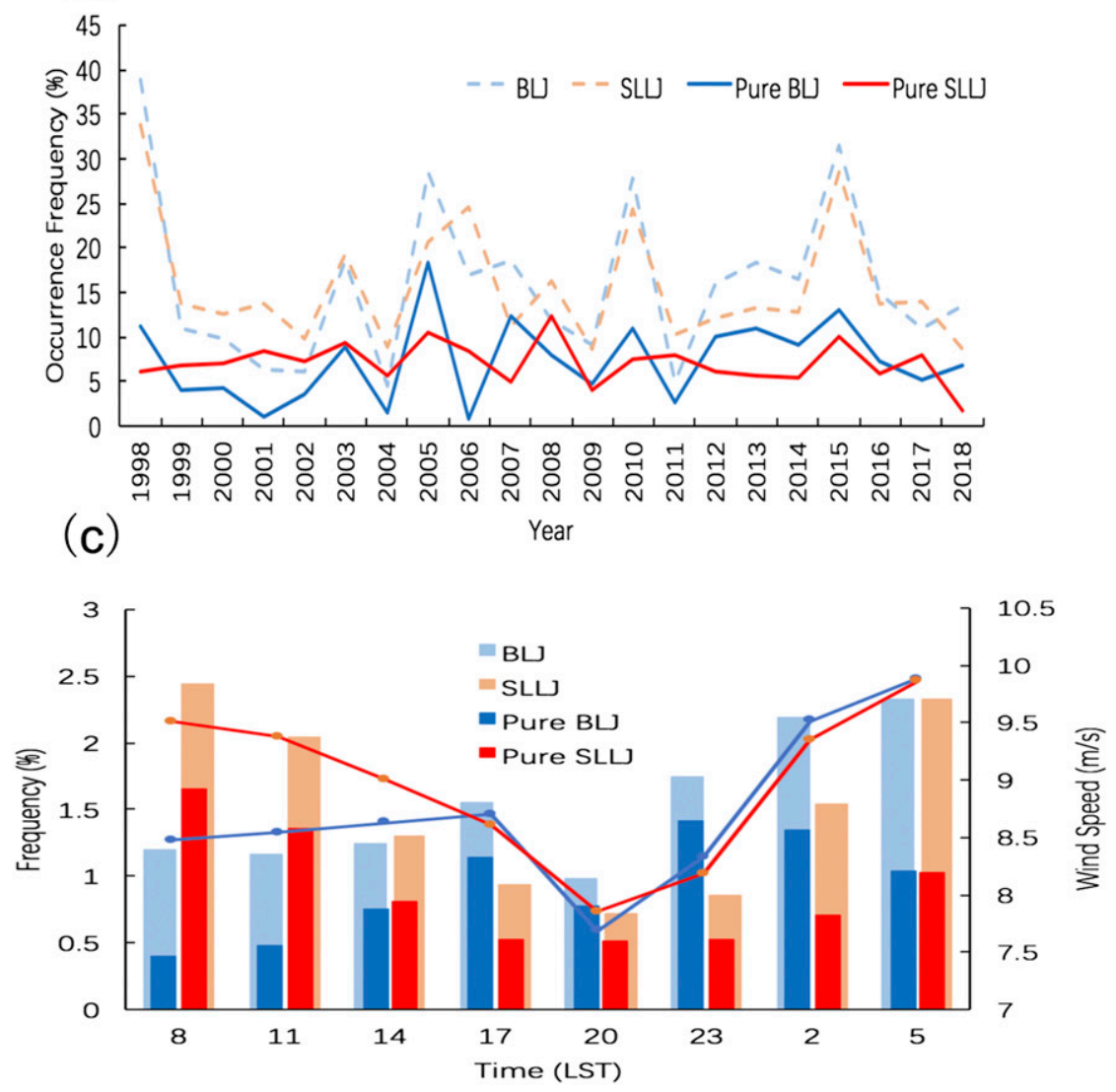

FIG. 2. (a) Seasonal variation of (pure) BLJ and (pure) SLLJ event occurrence frequency (\%) and average rainfall rate $\left(\mathrm{mm} \mathrm{h}^{-1}\right)$ over southern China (red box in Fig. 1). (b) Interannual variation of (pure) BLJ and (pure) SLLJ event occurrence frequency (\%) during the earlysummer rainy season from 1998 to 2018. (c) Diurnal cycle of (pure) BLJ and (pure) SLLJ event occurrence frequency $(\%)$ during the early-summer rainy season. Blue and red lines indicate wind speeds $\left(\mathrm{m} \mathrm{s}^{-1}\right)$ averaged in the lower and upper half of blue box in Fig. 1 during the BLJ and SLLJ days, respectively.

systems such as typhoons. Before the early-summer rainy season, rainfall in March-April mainly belongs to spring rainfall before the onset of the summer monsoon. In this study, we mainly focus on the period of the early-summer rainy season (May-June) when rainfall reaches its peak, and both BLJs and SLLJs are relatively active. In the section 6, we will briefly compare the periods of the spring, early-summer, and post-summer rainy seasons. 

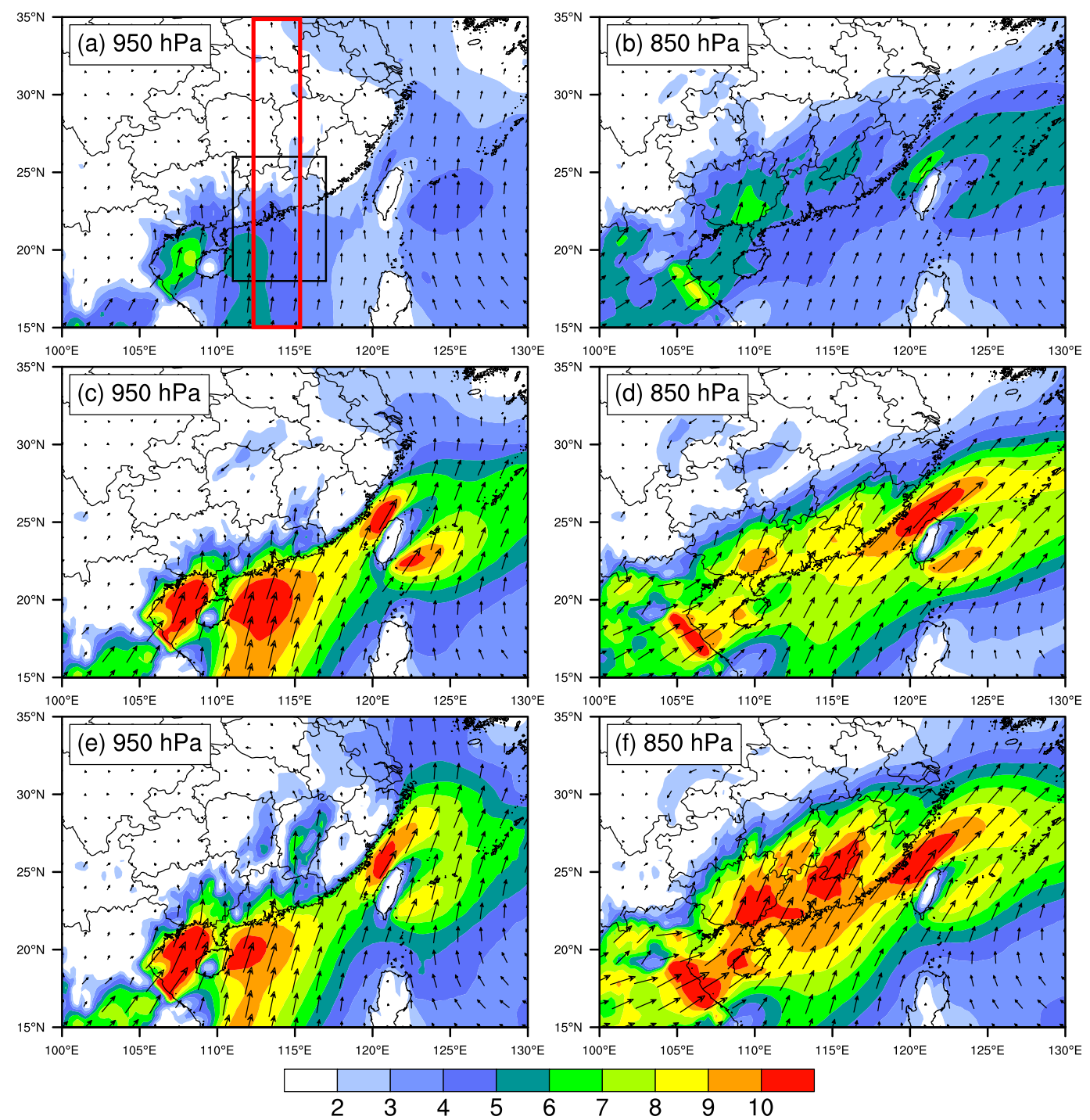

FIG. 3. Distribution of horizontal winds at (left) $950 \mathrm{hPa}$ and (right) 850 for (a),(b) the climate mean, (c),(d) pure BLJ events, and (e),(f) pure SLLJ events during the early-summer rainy season. The red box is used in Figs. 4 and 11.

Figure $2 b$ shows the interannual variations of BLJ and SLLJ event occurrences from 1998 to 2018. Both BLJ and SLLJ event occurrences have large variation between years, with standard deviations of $9.2 \%$ and $7.0 \%$, respectively. BLJ and SLLJ events have a notable relationship with each other in interannual variation (their correlation is around 0.86). However, if double LLJ events are excluded, the correlation between pure BLJ and SLLJ events becomes low (0.16), which indicates their independence.

\section{b. The structure of BLJS and SLLJS}

Figure 3 compares the composites of horizontal winds at different levels for the climate mean, BLJ events, and
SLLJ events during the early-summer rainy season. Generally, the winds at low levels near the south coast of China during the LLJ events $\left(6-10 \mathrm{~m} \mathrm{~s}^{-1}\right)$ are much stronger than those for the climate mean $\left(2-4 \mathrm{~m} \mathrm{~s}^{-1}\right)$. With regard to the composite of the BLJ events, a strong southerly wind maximum at $950 \mathrm{hPa}\left(\sim 10 \mathrm{~m} \mathrm{~s}^{-1}\right)$ occurs over the northern region of SCS (around $20^{\circ} \mathrm{N}, 112^{\circ} \mathrm{E}$ ) in addition to a wind core $\left(\sim 10 \mathrm{~m} \mathrm{~s}^{-1}\right)$ over the Gulf of Tonkin (around $20^{\circ} \mathrm{N}, 108^{\circ} \mathrm{E}$, Fig. 3c). As for the SLLJ events, southwesterly winds at $850 \mathrm{hPa}$ over southern China are stronger than those in the BLJ events, although the winds at $950 \mathrm{hPa}$ seem similar to or a little bit weaker than those in the BLJ events. Meanwhile, the strong $850-\mathrm{hPa}$ winds during SLLJ events can penetrate 


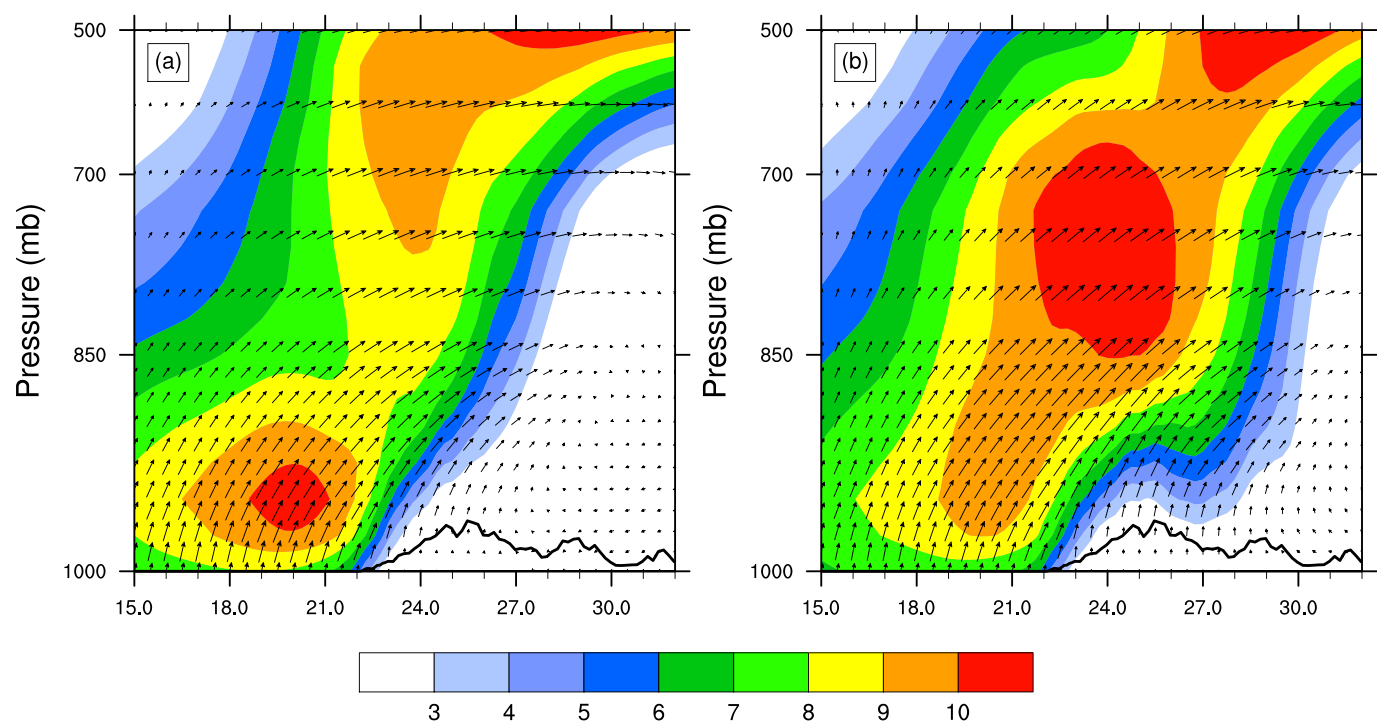

FIG. 4. Vertical structure of horizontal wind speed $\left(\mathrm{m} \mathrm{s}^{-1}\right)$ and vectors (upward means southerly wind) along the meridional direction averaged in the red box of Fig. 3a during the (a) pure BLJ events and (b) pure SLLJ events.

farther north compared to the BLJ events (cf. Figs. 3d and 3f).

To display the vertical structure of jets, south-north cross sections of winds averaged in the red box of Fig. 3a are shown in Fig. 4. Figure 4 clearly shows that the vertical structures of winds are significantly different for the BLJ and SLLJ events. In the vertical composite of the BLJ events, a wind maximum $\left(\sim 10 \mathrm{~m} \mathrm{~s}^{-1}\right)$ is located at the level of $950 \mathrm{hPa}$ and mainly over the ocean (around $20^{\circ} \mathrm{N}$ ) corresponding to a southerly BLJ (Fig. 4a). A westerly jet above $500 \mathrm{hPa}$ located to more north $\left(28^{\circ} \mathrm{N}\right)$ extends downward and results in relatively strong winds at $700 \mathrm{hPa}$ (Fig. 4a). In contrast, as for the SLLJ events, a wind maximum $\left(>10 \mathrm{~m} \mathrm{~s}^{-1}\right)$ occurs at $800 \mathrm{hPa}$ on land (around $24^{\circ} \mathrm{N}$ ), which corresponds to a southwesterly elevated SLLJ (Fig. 4b).

\section{c. Diurnal variation}

Besides interannual and seasonal variations, the occurrence frequencies of BLJ and SLLJ events also show a pronounced diurnal cycle (Fig. 2c). BLJs frequently occur at night (2300-0500 LST), whereas SLLJs often occur in the early morning (0500-1100 LST). When double LLJs are excluded, the difference of the diurnal peak of pure BLJ and SLLJ events becomes larger. Those results are generally in agreement with $\mathrm{Du}$ et al. (2014). The composite analysis of winds further exhibits differences in the diurnal cycle between BLJ days and SLLJ days (Fig. 5). During the BLJ days, the wind at $950 \mathrm{hPa}$ over the north region of SCS is strongest around $10 \mathrm{~m} \mathrm{~s}^{-1}$ at 0200-0500 LST. Unlike the BLJ days, the wind at $800 \mathrm{hPa}$ (the maximum level) over southern
China peaks later in the SLLJ days (0500-0800 LST). Figure 6 shows perturbation wind fields at $950 \mathrm{hPa}$ $(800 \mathrm{hPa})$ during the BLJ (SLLJ) days. The perturbation wind fields every $3 \mathrm{~h}$ are defined by the deviation of the wind fields at each time from the daily mean wind fields. The 950-hPa perturbation wind vectors (indicated by blue vectors in Fig. 6) clearly show the large-scale (planetary-scale) land-sea breeze circulation covering the East Asia-western North Pacific region, which is also found in Huang et al. (2010) and Huang and Chan (2011). Such large-scale sea breeze occurs during 23000500 LST with a clockwise rotation, while the large-scale land breeze occurs during 0800-1400 LST. It is noted that the time phase of large-scale land-sea breeze is typically later than that of local-scale land-sea breeze. The large-scale sea breeze probably contributes to nighttime peak of BLJ. Another possible reason is the downstream effect of Indochina Peninsula. The boundary layer winds over the northern South China Sea mainly come from the Indochina Peninsula. The boundary layer winds over the Indochina Peninsula show significant diurnal cycle with a maximum at night (Figs. 5 and 6) due to the Blackadar mechanism of inertial oscillation on land (Blackadar 1957; H. Kong et al. 2019, unpublished manuscript). A strong southwesterly wind over the Indochina Peninsula at night can partly account for the strong southerly wind over the northern South China Sea at night due to advection and the downstream effect. The diurnal cycle of $800-\mathrm{hPa}$ perturbation winds over southern China (indicated by red vectors in Fig. 6) clearly shows the veering of perturbation winds, probably 

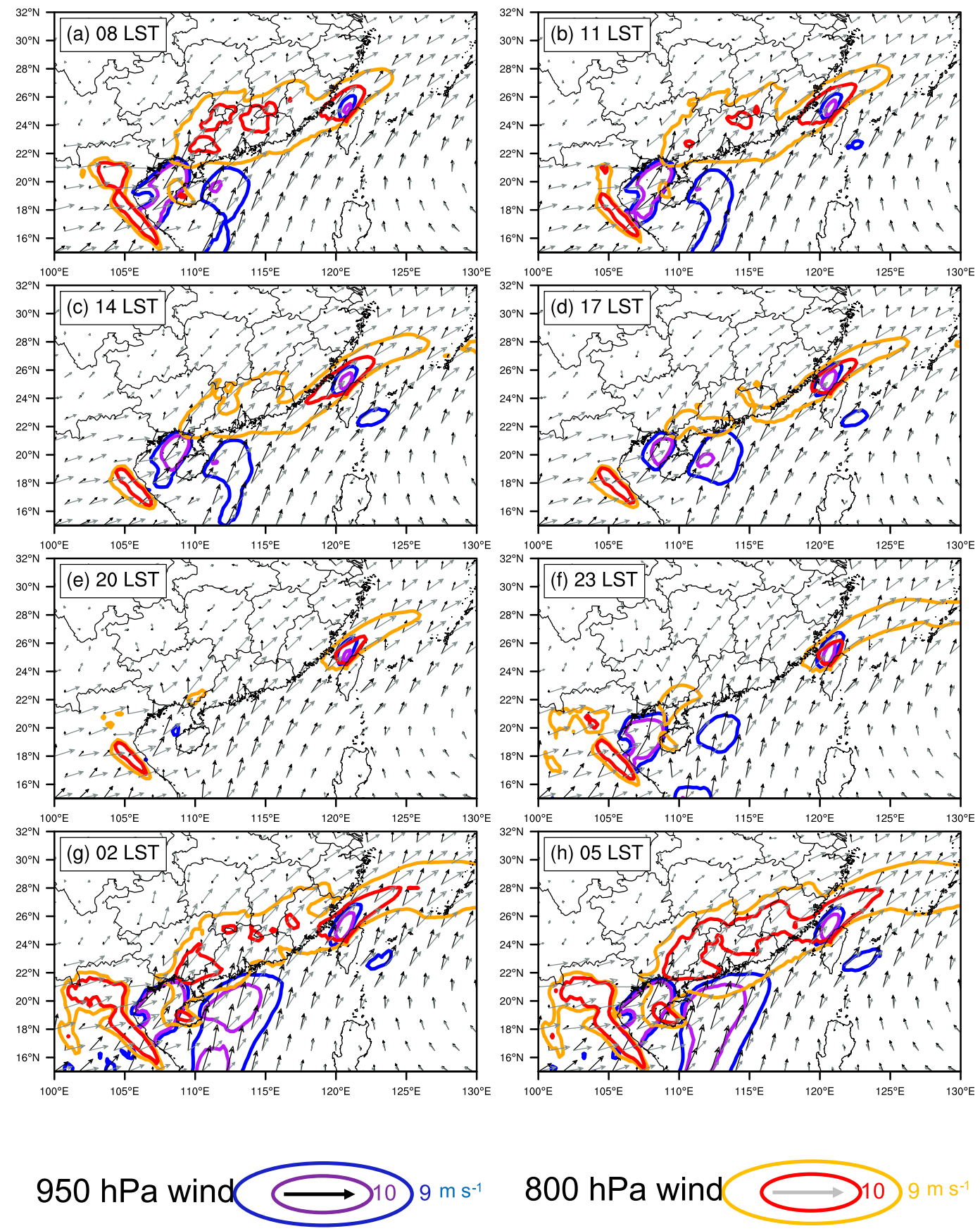

FIG. 5. Distribution of horizontal winds at $950 \mathrm{hPa}$ during the BLJ days (cold color contours of 9-10 $\mathrm{m} \mathrm{s}^{-1}$ and black vectors) and wind at $800 \mathrm{hPa}$ during the SLLJ days (warm color contours of $9-10 \mathrm{~m} \mathrm{~s}^{-1}$ and gray vectors) during the early-summer rainy season.

driven by large-scale mountain-plain solenoids (Chen et al. 2014a). Perturbation winds at $800 \mathrm{hPa}$ become southwesterly over southern China during 0500-0800 LST and thus lead to the maximum of the SLLJ in the early morning. However, the detailed mechanisms of the diurnal cycle of the BLJ and SLLJ, while beyond the scope of this study, deserve further study through a combination of high-resolution numerical simulations and observations.

\section{Rainfall patterns associated with LLJs}

In this section, we examine the relationship between LLJs and rainfall patterns. First, Fig. 7a presents the 

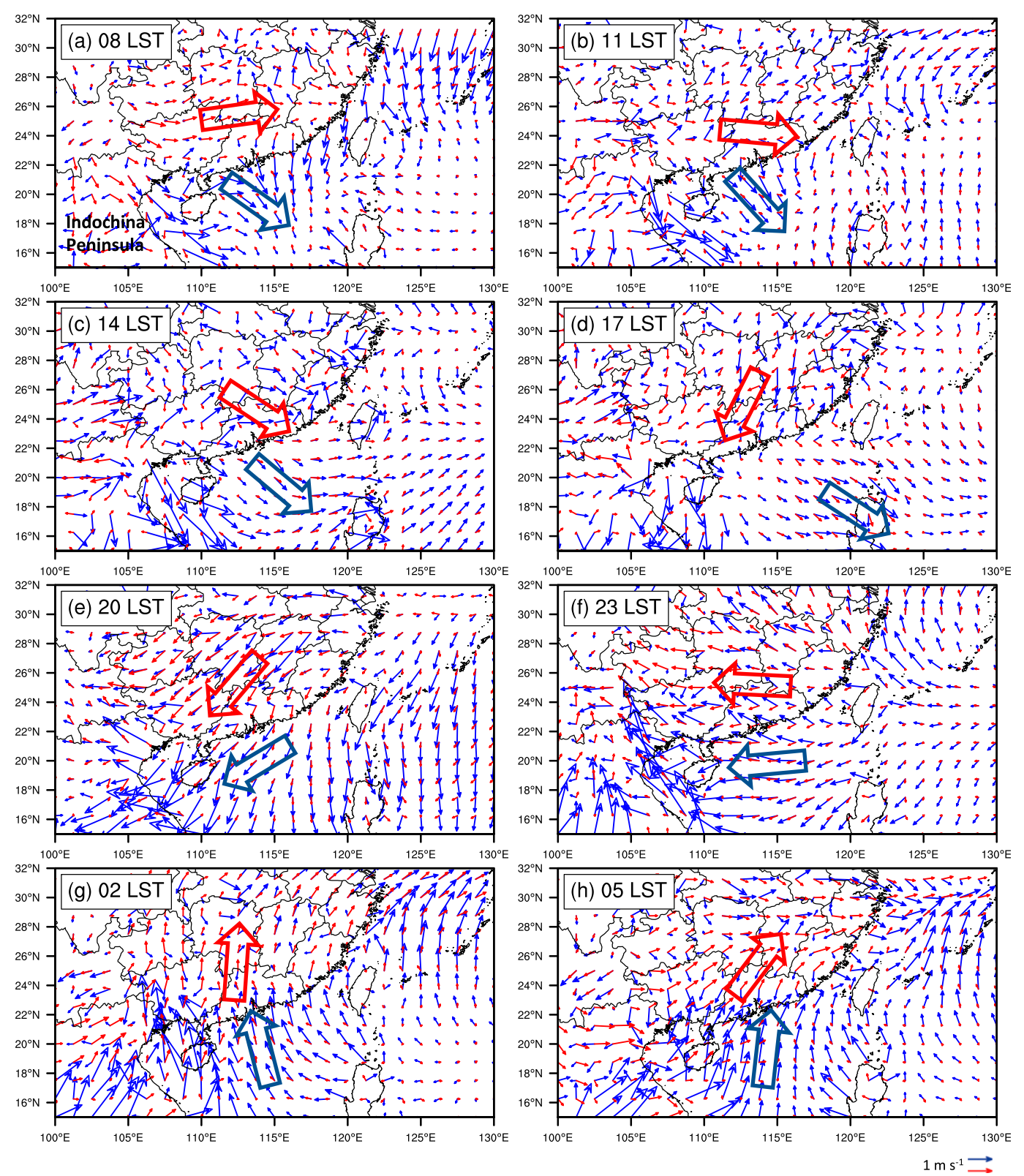

FIG. 6. Distribution of perturbation wind vectors at $950 \mathrm{hPa}$ during the BLJ days (blue) and perturbation wind vectors at $800 \mathrm{hPa}$ during SLLJ days (red) during the early-summer rainy season. Blue and red hollow arrows indicate the general direction of perturbation wind vectors at 950 and $800 \mathrm{hPa}$ over the northern South China Sea and southern China, respectively.

climatological horizontal distribution of rainfall during the early-summer rainy season (May-June). As expected, four rainfall maximum centers $\left(\sim 0.5 \mathrm{~mm} \mathrm{~h}^{-1}\right)$ exist over southern China consisting of two centers near the coasts (Yangjiang and Shanwei, labeled with letters a and b, respectively, in Fig. 7a) and two inland centers (Longmen and northeastern Guangxi, labeled with letters $\mathrm{c}$ and $\mathrm{d}$, respectively, in Fig. 7a), which are in agreement with Luo et al. (2017). Figure 7 compares the composites of rainfall for the pure BLJ events (Fig. 7b) and pure SLLJ events (Fig. 7c) with the climate mean (Fig. 7a). It clearly shows that rainfall in the pure BLJ events or SLLJ events are greatly strengthened over southern China compared to the climate state. Furthermore, the distributions of rainfall in the pure BLJ and SLLJ events differ from each other. During the pure BLJ events, a strong west-east-oriented rainband is located to the south of the Nanling and Wuyi Mountains and Yun-Gui Plateau (Fig. 7b). The maximum 

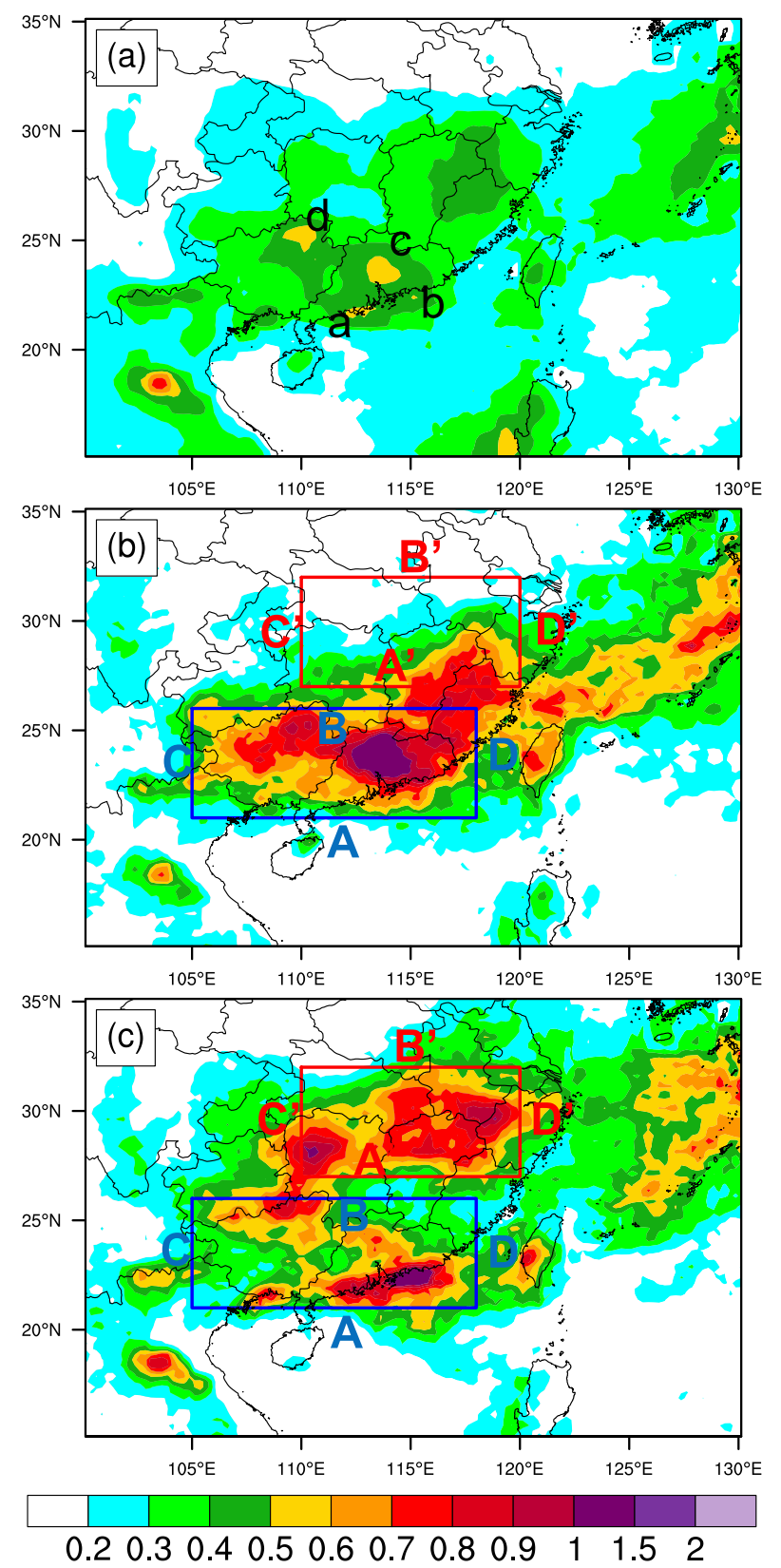

FIG. 7. Distribution of average rainfall rate $\left(\mathrm{mm} \mathrm{h}^{-1}\right)$ for (a) the climate mean, (b) pure BLJ events, and (c) pure SLLJ events during the early-summer rainy season.

of hourly average rainfall is $\sim 1 \mathrm{~mm} \mathrm{~h}^{-1}$ at $23^{\circ} \mathrm{N}, 114^{\circ} \mathrm{E}$ (south of the Nanling Mountains). Unlike pure BLJ events, there are two west-east-oriented rainbands for the composite of the pure SLLJ events (Fig. 7c). One is located at around $28^{\circ} \mathrm{N}$ and the other is near the south coast of China. The hourly average rainfall rate reaches maximum of around $1 \mathrm{~mm} \mathrm{~h}^{-1}$ near the coast or in the northern rainband. The northern rainband seems analogous to rainfall pattern along the east-west-oriented mei-yu front (Chen et al. 2017). Therefore, the two types of LLJ apparently influence the rainfall distribution over southern China. The related possible mechanisms will be discussed latter.

A statistical analysis of interannual variation is further conducted to explore the relationship between LLJs and rainfall. Figure 8 shows the scatterplots and linear regression of BLJ or SLLJ occurrence frequency versus rainfall amount over the south region (box $\mathrm{ABCD} ; 105^{\circ}-$ $118^{\circ} \mathrm{E}, 21^{\circ}-26^{\circ} \mathrm{N}$ ) and the north region (box $\mathrm{A}^{\prime} \mathrm{B}^{\prime} \mathrm{C}^{\prime} \mathrm{D}^{\prime}$; $110^{\circ}-120^{\circ} \mathrm{E}, 27^{\circ}-33^{\circ} \mathrm{N}$ ) of Fig. 7. Overall, LLJ occurrence frequencies are closely correlated to rainfall amount. BLJ occurrences are more associated with rainfall in the south region (correlation $R$ is 0.56 ) compared to the north region $(R=0.32$; Figs. 8a,b). The former, with magnitudes greater than 0.41 , is statistically from zero at the $95 \%$ confidence level using a two-tailed significance test, but the latter is not. In addition, SLLJ occurrences are linked to rainfall in both the north and south regions where linear correlations are 0.50 and 0.59 , respectively (Figs. 8c,d). The correlations above will be further explained by the impact mechanisms of LLJs on rainfall in section 5.

Since the BLJs and SLLJs have an obvious diurnal cycle as shown in Figs. 2c and 5, it is interesting to examine the diurnal cycle of rainfall under the effect of BLJs or SLLJs. In the climatological diurnal cycle of rainfall, rainfall in the south region exhibits an obvious peak in the afternoon (1700 LST; Fig. 9b). During pure BLJ or SLLJ events, a nighttime peak (0500 LST) appears besides the afternoon peak (Fig. 9b). There are thus double peaks in the diurnal cycle. The additional nighttime peak occurs because BLJs or SLLJs with a maximum at night facilitate nocturnal rainfall in the south region. The impact of BLJs on the diurnal cycle is more significant than that of SLLJs. As for rainfall in the north region (Fig. 9a), weak double peaks exist climatologically with maxima in the afternoon (1700 LST) and morning (0800 LST). Under the effect of the SLLJs and BLJs, the early morning peak becomes much more distinct but the afternoon peak becomes weak accordingly.

\section{Possible impact mechanisms of LLJs on rainfall}

In the present section, we reveal possible impact mechanisms of LLJs on rainfall and distinguish the differences between the BLJ and SLLJ. The effects of terrain, synoptic disturbances, and moisture transportation are considered and discussed.

\section{a. Topographic effects on low-level lifting under the two types of $L L J S$}

As mentioned in section 4, rainfall is mainly confined to the south (windward) side of the Nanling and Wuyi 

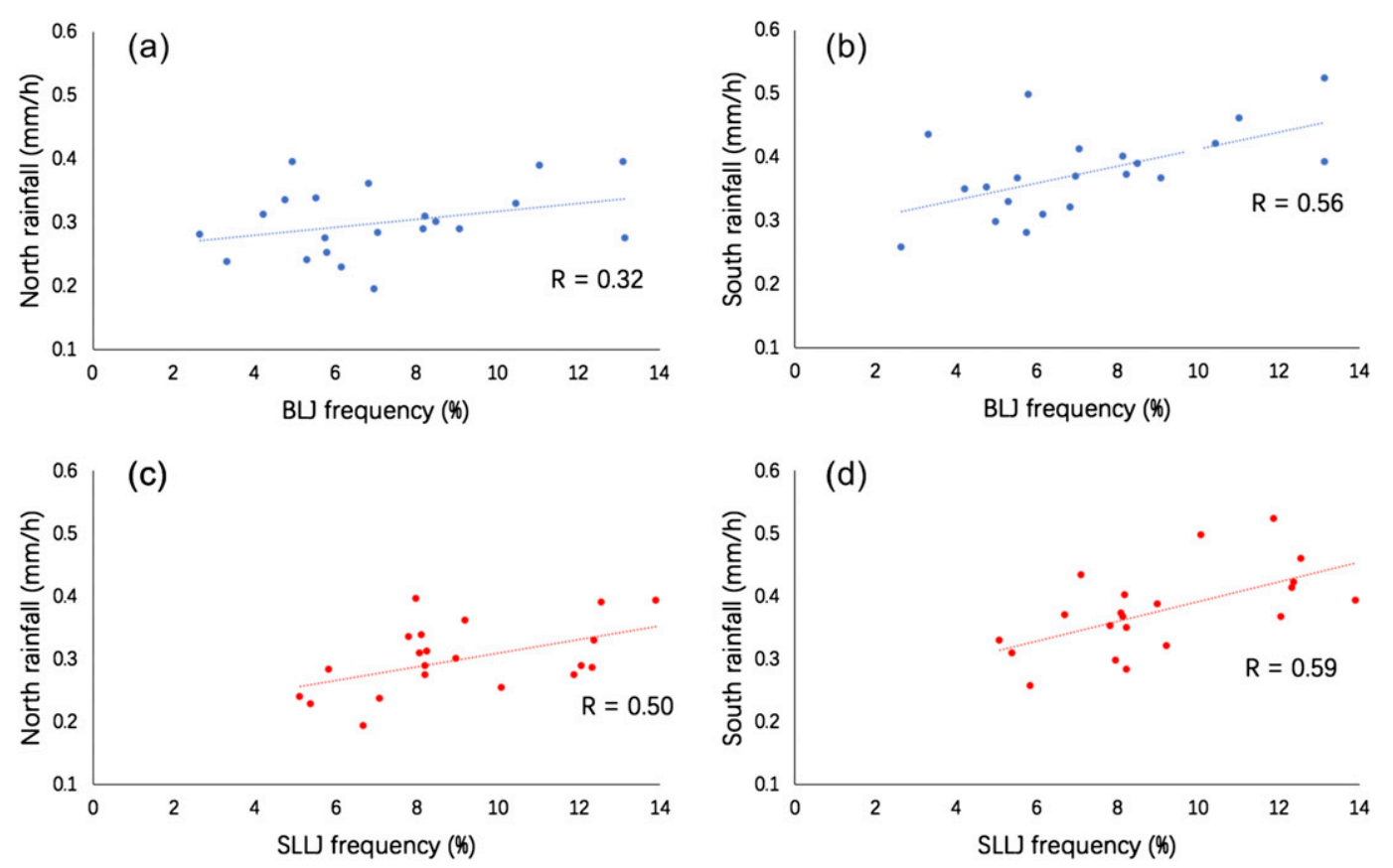

FIG. 8. Scatterplots and linear regression lines of (top) BLJ or (bottom) SLLJ frequency (\%) vs average rainfall rate $\left(\mathrm{mm} \mathrm{h}^{-1}\right)$ over the (a), (c) north region and (b),(d) south region during the early-summer rainy season of 19982018; $R$ is the correlation coefficient.

Mountains and Yun-Gui Plateau during the pure BLJ events, whereas rainfall can extend farther north in addition to the coastal rainfall during the pure SLLJ events.

Figure 10 indicates that the composite of convergence/ divergence at $950 \mathrm{hPa}$ is indeed closely related to the topography. During the BLJ events, an obvious $950-\mathrm{hPa}$ convergence zone occurs to the south of the Nanling Mountains and Wuyi Mountians and the Yun-Gui Plateau (Fig. 10a). On the leeside of those high terrains, convergence/divergence is relatively weak (Fig. 10a). In contrast, during the pure SLLJ events, a convergence zone still exists on the windward side of the mountains (indicated by a blue box in Fig. 10b). Meanwhile, divergence occurs on the leeside of mountains (indicated by a red box), and weak convergence also happens farther north (indicated by a green box in Fig. 10b). Such differences in convergence/divergence patterns are generally consistent with rainfall patterns during the pure BLJ and SLLJ events.

Figures $11 \mathrm{a}$ and $11 \mathrm{~b}$ further present the vertical cross sections of vertical motion and meridional winds along the meridional direction averaged in the red box of Fig. 3a during the BLJ events and SLLJ events. Figures $11 \mathrm{c}$ and $11 \mathrm{~d}$ manifest as the corresponding zonal averaged rainfall. The peak of the Nanling mountain range is located at around $25^{\circ} \mathrm{N}$, while the coast is at around $21^{\circ} \mathrm{N}$. During the pure BLJ events, a strong southerly BLJ over the ocean impinges on the Nanling Mountains, producing strong orographic lifting on the upside of the mountains (Fig. 11a). On the leeside of the mountains, the southerly winds become very weak due to the obstacle of the mountains. The rainfall therefore mainly occurs on the windward side of mountains during the pure BLJ events owing to the orographic lifting (Figs. 7b and 11a). In contrast, the strong winds of SLLJs are elevated (within 850-700 hPa), and thus they can overpass the Nanling Mountains. Upward motion occurs on the windward side of mountains and downward motion concurrently appears on the leeside (Fig. 11b). Moreover, additional upward motion redevelops downstream of the leeside downward motion, which agrees with the feature of leeside hydraulic jump (Rotunno and Bryan 2018). The effect of hydraulic jump seems to explain the upward motion that extends more north during the SLLJ events compared to that during the BLJ events (cf. Figs. 11a and 11b). Near the coast, the upward motion area is also broader in the pure SLLJ event than the pure BLJ events.

Therefore, the terrain effects on low-level flows greatly affect the patterns of convergence/divergence and vertical motions, thereby regulating the distributions of rainfall (Figs. 7b,c and 11c,d). Since BLJs and SLLJs have different vertical structures, their impacts on rainfall are different correspondingly. Owing to the terrain effects, BLJs are closely related to rainfall in 

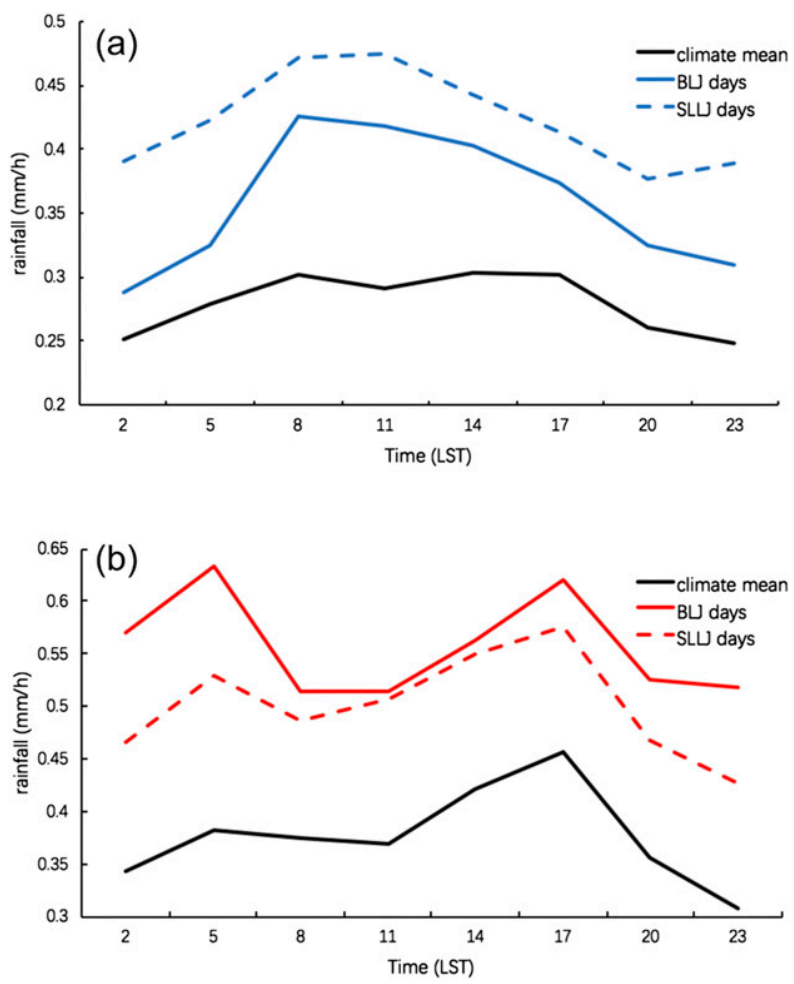

FIG. 9. Diurnal cycle of rainfall rate $\left(\mathrm{mm} \mathrm{h}^{-1}\right)$ averaged over the (a) north region and (b) south region during whole days, BLJ days, and SLLJ days during the early-summer rainy season.

the south region (windward side of mountains) thus exhibiting their high correlation (Fig. 8b). SLLJs are closely associated with rainfall in both north and south regions with high correlations (Figs. $8 \mathrm{c}, \mathrm{d}$ ) because SLLJs with larger vertical extent produce convergence not only in the boundary layer near the coasts $\left(\sim 22^{\circ} \mathrm{N}\right)$ and but also at the SLLJ terminus $\left(\sim 28^{\circ} \mathrm{N}\right.$; $850-700 \mathrm{hPa})$. It is noted that the regression correlation between SLLJs and rainfall over the south region is a little bit higher than that over the north region. This might be so because, in addition to convergence in the boundary layer near the coasts, SLLJs might induce $850-\mathrm{hPa}$ divergence at the entrance of SLLJ near the coast (not shown), which further benefits mesoscale lifting near the coast (Du and Chen 2019).

\section{b. Synoptic disturbances associated with the two types of $L L J S$}

SLLJs over southern China are found to be closely related to the mei-yu fronts or synoptic low pressure systems (Du et al. 2014; Chen et al. 1994; Du and Chen 2018). Figure 12 shows the composite of $850-\mathrm{hPa}$ geopotential anomalies in the pure BLJ and SLLJ events. Geopotential anomalies are calculated by the deviations of averaged geopotential during the pure BLJ or SLLJ
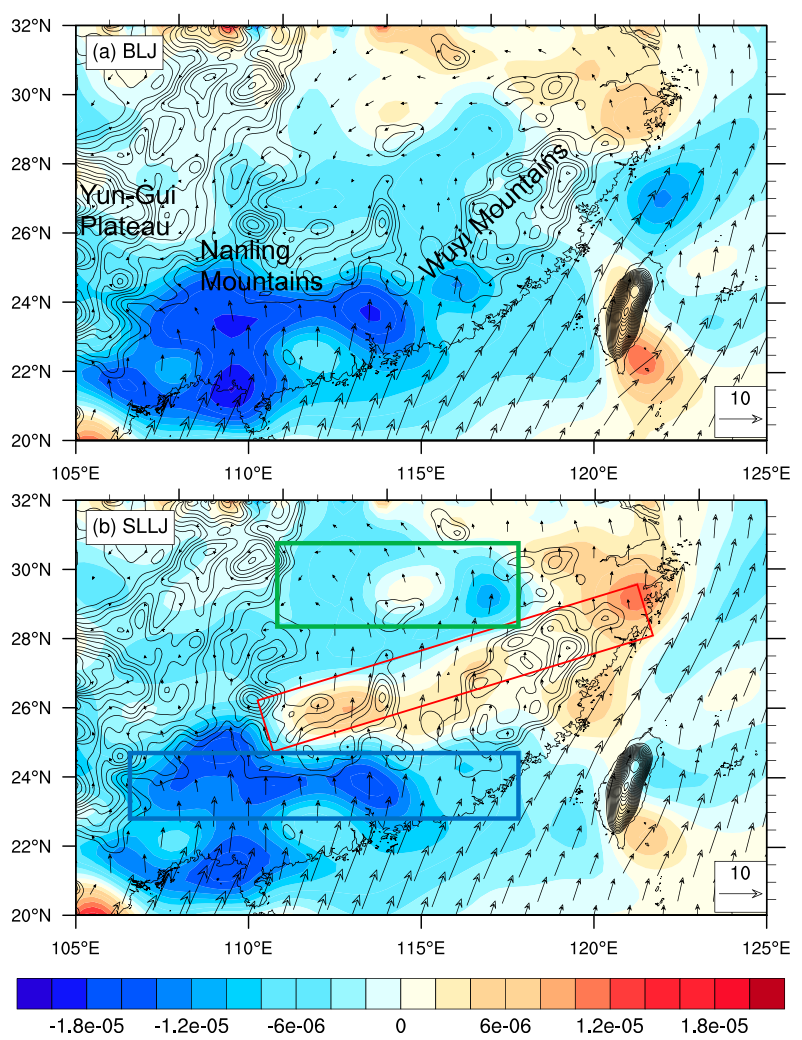

FIG. 10. Distribution of divergence (shading; $\mathrm{s}^{-1}$ ) and wind vectors $\left(\mathrm{m} \mathrm{s}^{-1}\right)$ at $950 \mathrm{hPa}$ for the (a) pure BLJ events and (b) pure SLLJ events during the early-summer rainy season. Black contours indicate terrain height ( $>400 \mathrm{~m}$ with an interval of $100 \mathrm{~m}$ ).

events from the climatological average. A relatively weak nearly west-east-oriented zone of the low pressure anomaly is located at around $30^{\circ} \mathrm{N}$, and the corresponding weak high pressure anomaly is located to the south during the pure BLJ events (Fig. 12a). In contrast, during the pure SLLJ events, the low pressure anomaly is stronger and centered at $29^{\circ} \mathrm{N}, 109^{\circ} \mathrm{E}$ (Fig. 12b). The corresponding high pressure anomaly is situated to the southeast of the low pressure anomaly. Such a pressure pattern is beneficial to the development of southwesterly geostrophic winds at $850 \mathrm{hPa}$ in the region between the low pressure and high pressure anomalies where a strong pressure gradient exists. The strong low pressure anomaly indicates that active synoptic disturbances exist over southern China in association with stationary or cold front troughs and embedded mesoscale convective systems or vortices. Such synoptic disturbances are always accompanied by rainfall. SLLJs frequently form and develop on the southeast side of low pressure disturbances (Matsumoto et al. 1971; Akiyama 1973). SLLJs are located to the south of rainfall as a part of the secondary circulation driven by convective latent heating (Chen and Yu 1988; Chen 1982; Chou et al. 

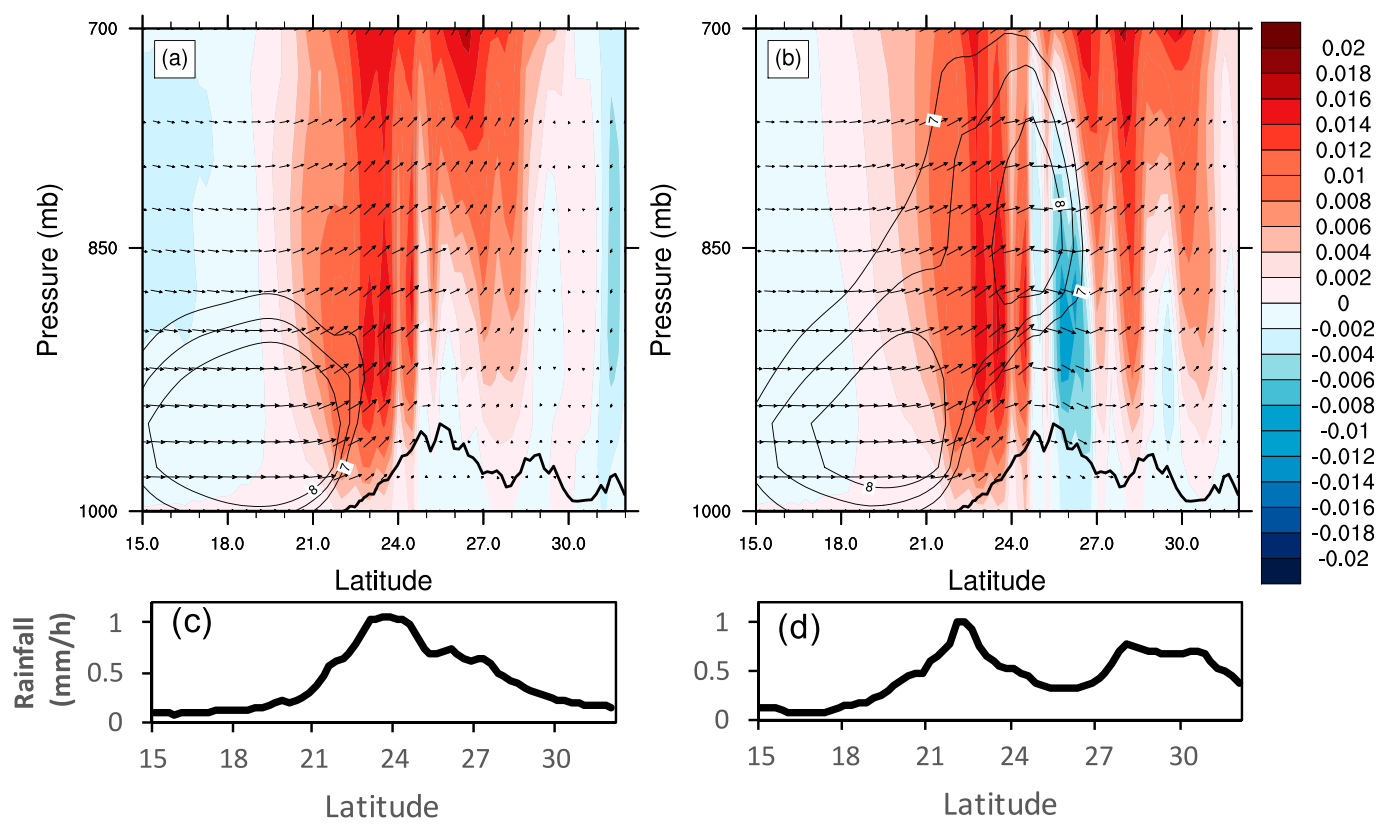

FIG. 11. (top) Vertical cross section of vertical motion (shading; $\mathrm{m} \mathrm{s}^{-1}$ ), meridional wind speed (contour $\geq 7 \mathrm{~m} \mathrm{~s}^{-1}$ with interval of $0.5 \mathrm{~m} \mathrm{~s}^{-1}$ ), and wind vectors (meridional wind vs $400 \times$ vertical motion), and (bottom) average rainfall rate $\left(\mathrm{mm} \mathrm{h}^{-1}\right)$ along meridional direction averaged in the red box of Fig. 3a the during the (a),(c) pure BLJ events and (b),(d) pure SLLJ events during the early-summer rainy season.

1990). Therefore, SLLJs might be related to the rainfall in the north region (Fig. 7c). Rainfall in the north region, however, is almost absent during the BLJ events without SLLJ (Fig. 7b).

The locations and intensity of synoptic disturbances (low pressure systems) are further examined in the pure BLJ and SLLJ events (Fig. 13). Blue and red dots indicate the centers of low pressure systems at $850 \mathrm{hPa}$ in the pure BLJ and SLLJ events, respectively. The intensity of low pressure systems is represented by the size of dots. The low pressure systems in the SLLJ events mainly occur over the land, particularly in the Sichuan basin, central-east China, and East China Sea (indicated by a red ellipse in Fig. 13). They also coincide with the preferred locations of low-level vortices, which are similar to those during the mei-yu season of central China (Chen et al. 2014x; Fu et al. 2013). Chen et al. (2017) studied a case of heavy rainfall occurring to the northern edge of monsoon flow at night or in the early morning, and found that two mesosynoptic vortices existed at the Sichuan basin and east coast near the quasistationary mei-yu front (their Fig. 2f), which favored convection in a latitudinal band. SLLJs play a role in conveying moisture, as shown in next subsection, while low-level vortices strengthen flow confluence and cyclonic wind shear that result in moisture convergence (Sun and Zhang 2012; Chen et al. 2017). As a comparison, the locations of low pressure systems during the
BLJ events are scattered in a relatively wide areas of subtropical East Asia. The strong low pressure systems tend to occur far over the ocean. Therefore, more synoptic distributions occur over or near southern China during the pure SLLJ events compared to BLJ events, which is beneficial to rainfall to the north of SLLJ.

\section{c. Moisture budget regulated by the two types of LLJS}

In this subsection, we examine the regional moisture budget associated with the LLJs. At first, we check the specific humidity anomalies in the pure BLJ and SLLJ events (Fig. 14). The calculation of specific humidity anomalies is similar to that of geopotential anomalies introduced in the subsection above. The specific humidity anomalies at $950 \mathrm{hPa}$ are higher than that at $850 \mathrm{hPa}$ in the pure BLJ events (Figs. 14a,c), whereas the specific humidity anomalies are significant at both 950 and $850 \mathrm{hPa}$ in the SLLJ events (Figs. 14b,d). The moisture is confined at lower levels and near the coast in the pure BLJ events, while the high moisture zone is located farther north (around $29^{\circ} \mathrm{N}$ ) in the pure SLLJ events. The differences in specific humidity anomalies between the two types of events might be attributed to the moisture transportation by low-level winds. During the pure SLLJ events, the strong low-level winds extend more north and thus transport more moisture from the south (ocean) to the north. Higher moisture anomalies around $29^{\circ} \mathrm{N}$ coincide with more rainfall in the north region (Fig. 7b). 

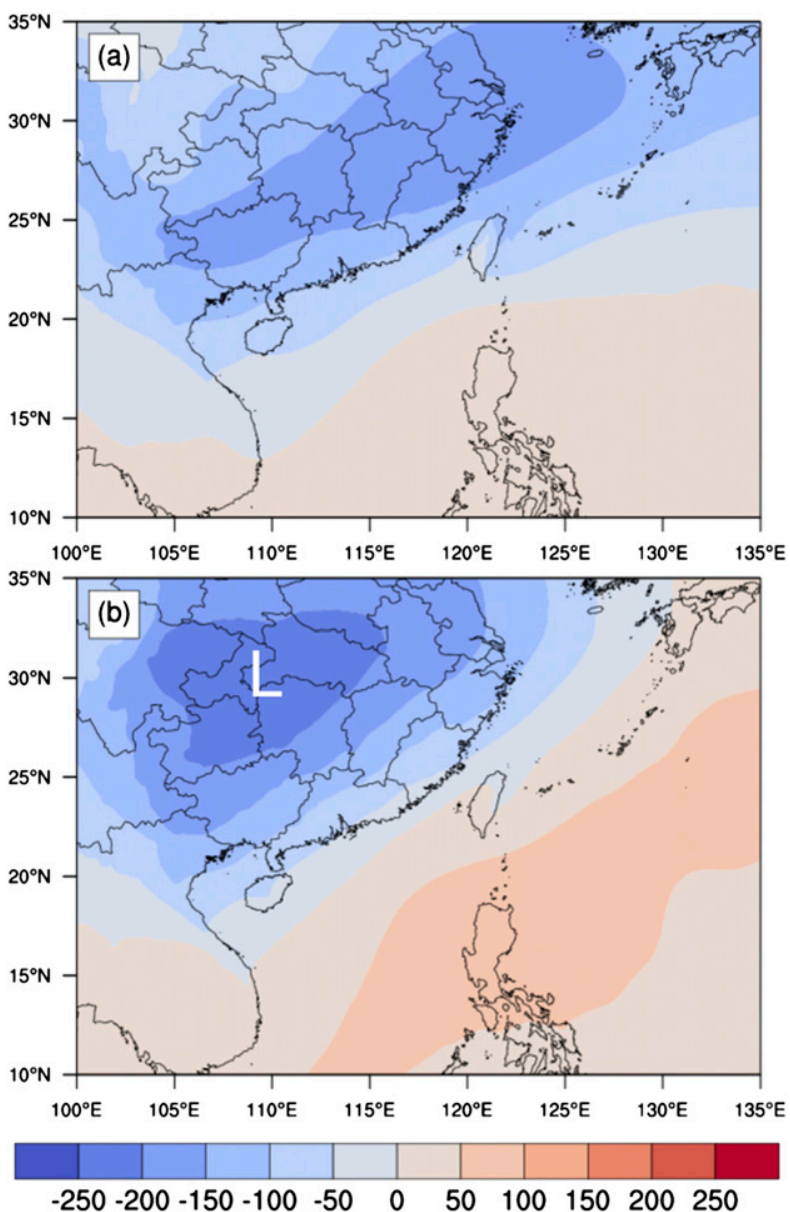

FIG. 12. Distribution of geopotential anomalies $\left(\mathrm{m}^{2} \mathrm{~s}^{-2}\right)$ at $850 \mathrm{hPa}$ during the (a) pure BLJ events and (b) pure SLLJ events during the early-summer rainy season.

Next, we further examine the horizontal moisture transport associated with the BLJ and SLLJ. Figures 15 and 16 show the vertical sections of moisture fluxes $(Q=\rho q V)$ through the planes $\mathrm{A}^{\prime}-\mathrm{D}^{\prime}$ of the north region and the planes A-D of the south region in the pure BLJ and SLLJ events. The fluxes directed into the box (region) are positive. During the pure BLJ events, the moisture fluxes through plane A (the south side of the south region) are positive and pronounced at lower layers (Fig. 15e). The maximum of fluxes occurs at around $975 \mathrm{hPa}$ and exceeds $0.16 \mathrm{~kg} \mathrm{~m}^{-2} \mathrm{~s}^{-1}$. Such high low-level moisture fluxes are related to high specific humidity at low levels near the coasts and strong low-level southerly winds due to the BLJ. The moisture fluxes through plane B (the north side of the south region) are mainly negative and more elevated, but their intensity is relatively weak (Fig. 15f). In addition, the moisture fluxes go through plane $\mathrm{C}$ (plane D) on the west (east) side into (out of) the south region, and their contributions to the net fluxes are

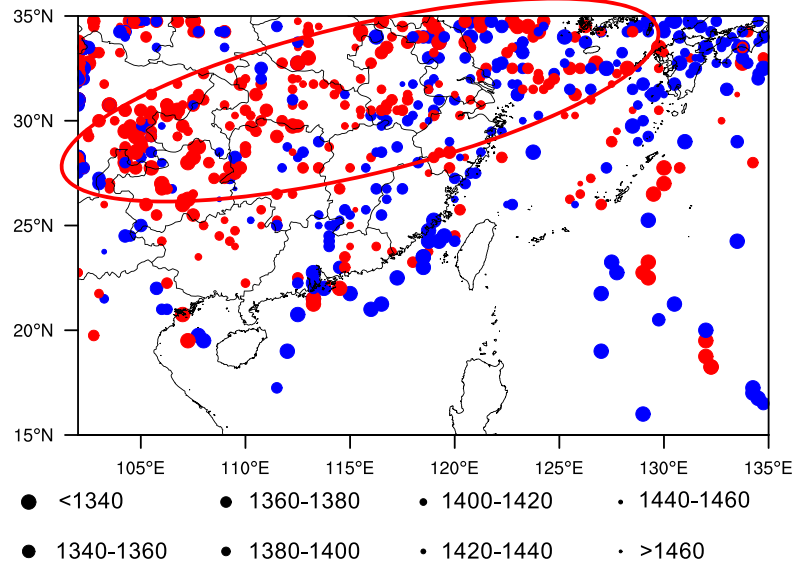

FIG. 13. Locations of low pressure centers at $850 \mathrm{hPa}$ during the pure BLJ events (blue dots) and pure SLLJ events (red dots). The size of the dots indicates the intensity of the low pressure systems (lowest geopotential height; gpm).

small (Figs. 15g,h). Compared to planes A-D of the south region (Figs. $15 \mathrm{e}-\mathrm{h}$ ), the moisture fluxes on plane $\mathrm{A}^{\prime}-\mathrm{D}^{\prime}$ of the north region are relatively inconspicuous (Figs. 15a-d). Since there is a strong (weak) positive moisture net flux in the south (north) region, rainfall therefore mainly occur in the south region rather than the north region during the pure BLJ events.

During the pure SLLJ events, the moisture fluxes through plane $\mathrm{A}$ is as distinct as those during the BLJ events (cf. Figs. 16e and 15e), but the elevated moisture fluxes through plane $\mathrm{B}$ out of the south region are stronger compared to the BLJ events (cf. Figs. 16f and 15f). Since strong SLLJs convey more moisture to the north, the moisture fluxes through plane $\mathrm{A}^{\prime}$ are more obvious compared to the BLJ events (cf. Figs. 16a and 15a). The maximum of the moisture fluxes through plane $\mathrm{A}^{\prime}$ occurs around the levels of $900-850 \mathrm{hPa}$, which are higher than the level of the moisture flux maximum through plane $\mathrm{A}$. The moisture fluxes through plane $\mathrm{B}^{\prime}$ (out of the north region) are very minor. Therefore, in addition to rainfall in the south region, rainfall occurs in the north region during the SLLJ events.

Figure 17a further illustrates the vertical profile of net moisture flux for the north and south regions, that is the sum of plane integration of the moisture fluxes for the four boundaries as

$$
\bar{Q}=\overline{Q_{\text {plane_A }}}+\overline{Q_{\text {plane_B }}}+\overline{Q_{\text {plane_C }}}+\overline{Q_{\text {plane_D }}} .
$$

As shown in Fig. 17a, the daily mean net moisture fluxes for the south region are mainly contributed from the boundary layer (below $925 \mathrm{hPa}$ ), whereas the net moisture fluxes for the north region mainly come from the layers of $925-700 \mathrm{hPa}$. The net moisture fluxes in the BLJ and SLLJ 

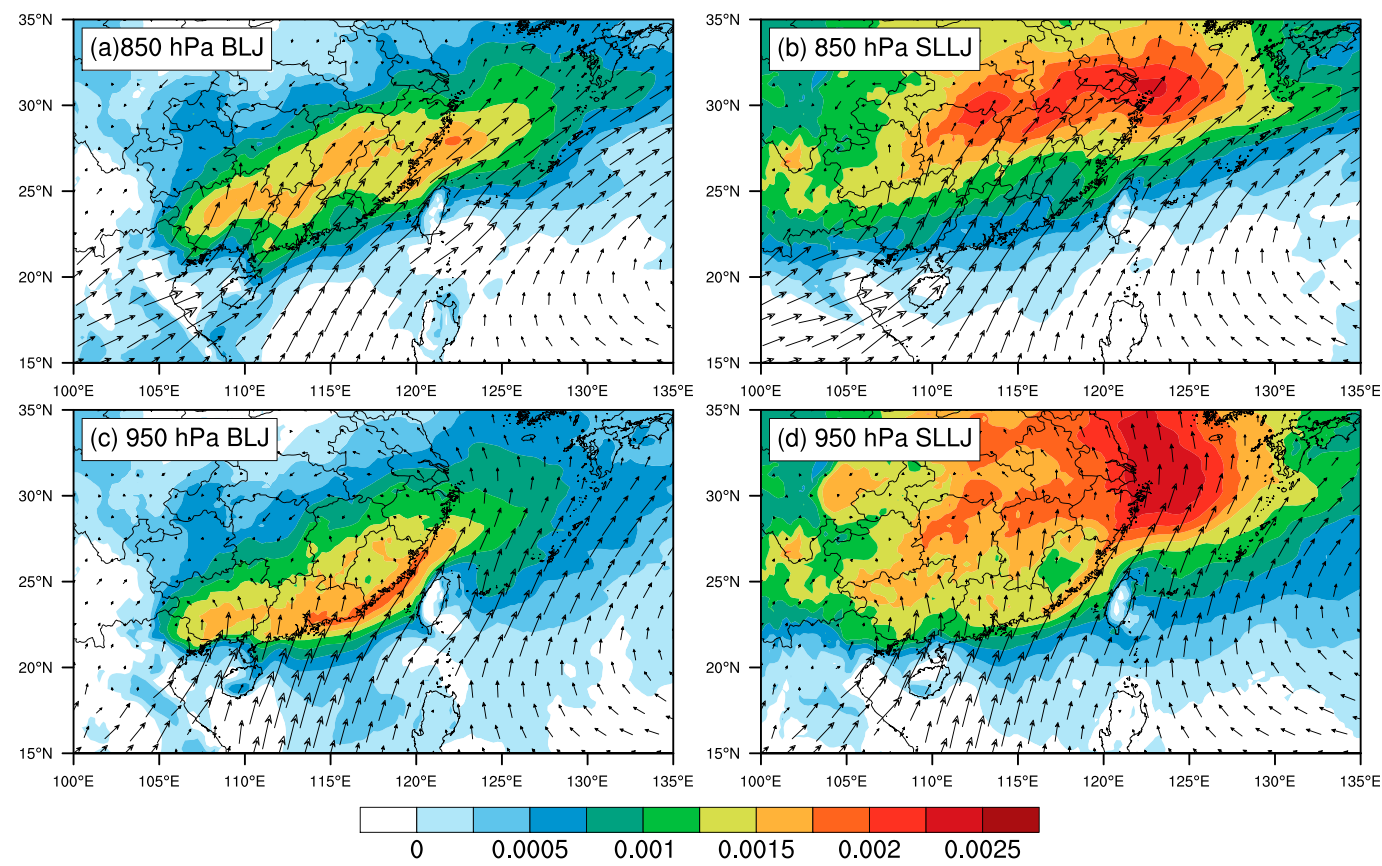

FIG. 14. Composite of specific humidity anomalies (shading; $\mathrm{kg} \mathrm{kg}^{-1}$ ) horizontal winds at (top) 850 and (bottom) $950 \mathrm{hPa}$ during the (a),(c) pure BLJ events and (b),(d) pure SLLJ events during the early-summer rainy season.

events are different in intensity (Fig. 17a). The net moisture fluxes of the south region in the pure BLJ events with a maximum of $185 \mathrm{~kg} \mathrm{~m}^{-1} \mathrm{~s}^{-1}$ at $975 \mathrm{hPa}$ are larger than that in the pure SLLJ events with a peak of $155 \mathrm{~kg} \mathrm{~m}^{-1} \mathrm{~s}^{-1}$. The maximum moisture convergence of the south region for the pure BLJ and SLLJ events appears at the same altitude ( $975 \mathrm{hPa})$. It is because 1) a higher specific humidity occurs in the lower level, and 2) both BLJ and SLLJ bring strong
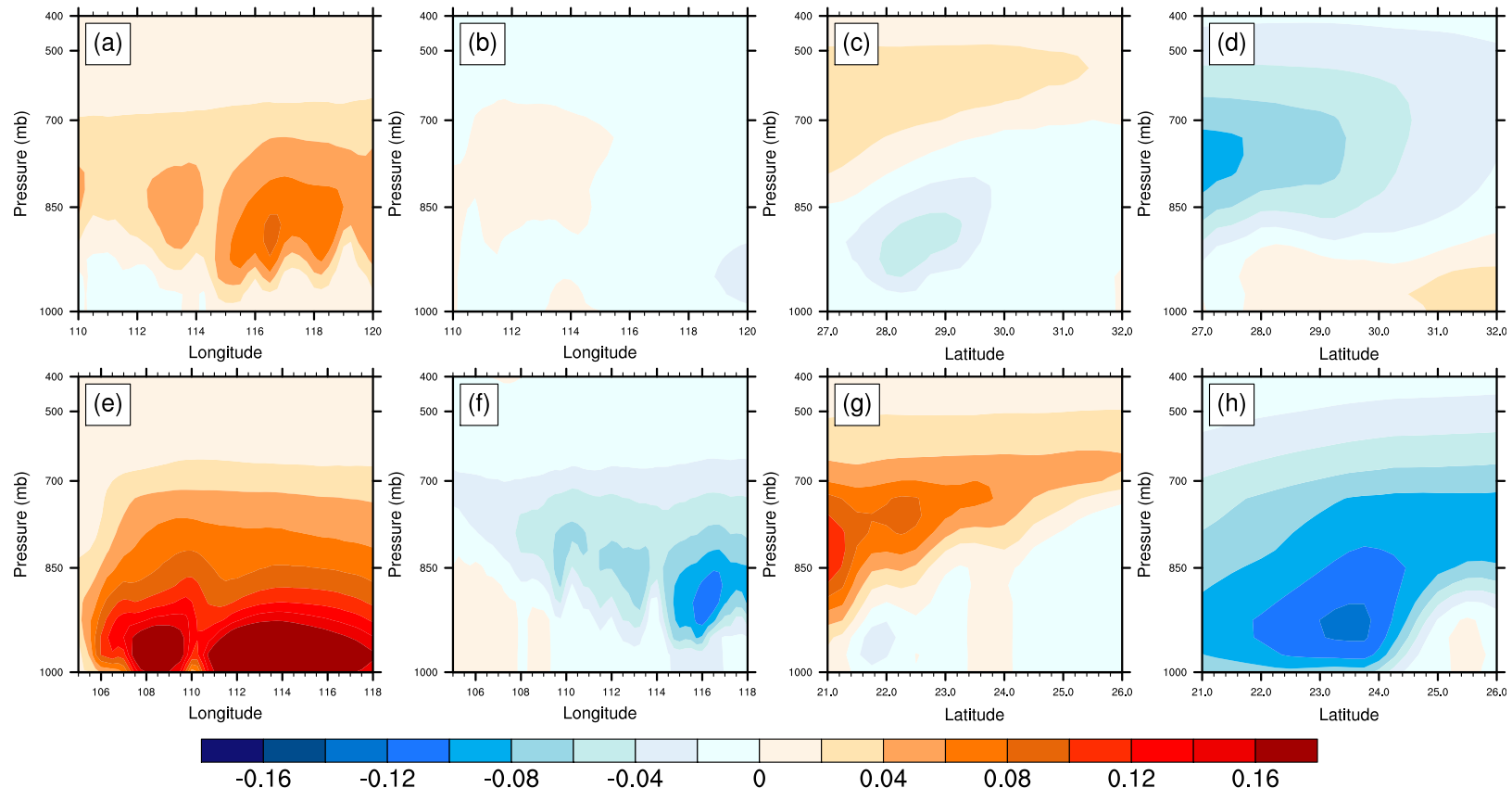

$-0.08$

$-0.04$

0.08

0.12

0.16

Fig. 15. Vertical cross sections of moisture flux (shading; $\mathrm{kg} \mathrm{m}^{-2} \mathrm{~s}^{-1}$ ) through planes (a) $\mathrm{A}^{\prime}$, (b) $\mathrm{B}^{\prime}$, (c) $\mathrm{C}^{\prime}$, (d) $\mathrm{D}^{\prime}$, (e) A, (f) B, (g) C, and (h) D in Fig. 7 during the pure BLJ events during the early-summer rainy season. 

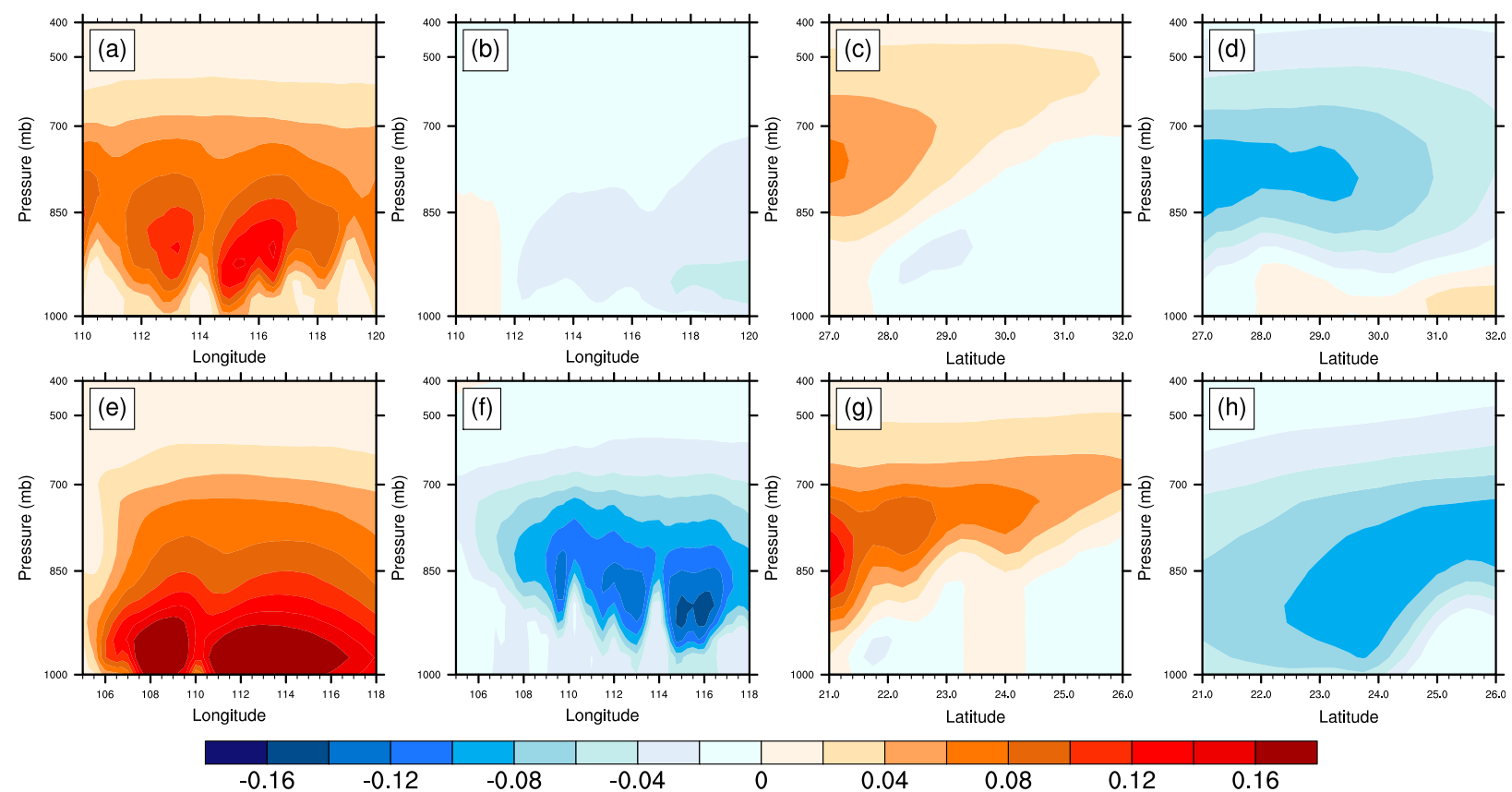

$-0.16$ $-0.12$

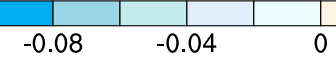

0.04

0.08

0.12

0.16

FIG. 16. As in Fig. 15, but for the pure SLLJ events.

boundary layer winds near the coast and thus cause a large moisture convergence on the windward side of the terrain due to the terrain obstruction effect. As for the north region, the net moisture fluxes in the SLLJ events with a maximum of $50 \mathrm{~kg} \mathrm{~m}^{-1} \mathrm{~s}^{-1}$ at $900 \mathrm{hPa}$ are in turn larger than those in the BLJ events with a peak of $25 \mathrm{~kg} \mathrm{~m}^{-1} \mathrm{~s}^{-1}$ at $850 \mathrm{hPa}$.

From the 3-hourly evolution of the net moisture flux (Figs. 17b,c), we explain the diurnal cycle of rainfall in the north and south regions. Similar to the diurnal cycle of rainfall and LLJ event occurrence, the net moisture fluxes related to BLJ or SLLJ exhibit an obvious diurnal cycle. During the pure BLJ events, the net moisture flux of the south region reaches a maximum during 2300-0500 LST (Fig. 17b), coinciding with the diurnal cycle of BLJ occurrence (Fig. 2c). In addition, the net moisture flux of the north region maximizes during 0200-0800 LST in the pure SLLJ events (Fig. 17c), which is also in agreement with the diurnal cycle of SLLJ event occurrence (Fig. 2c).

Through the above analyses of the moisture budget, we thus conclude that the distribution and diurnal cycle of rainfall are greatly affected by the moisture transport and convergence at the lower troposphere due to the SLLJ and BLJ.

\section{Discussion on seasonal variation of the LLJs' impact on rainfall}

As exhibited above (Fig. 2a), both rainfall and LLJs exhibit distinct seasonal variations. The present study mainly focuses on the LLJs' impact on rainfall in the early-summer rainy season (May-June) when accumulated rainfall in South China reaches its annual peak, and both the BLJ and SLLJ are relatively active. However, the impact of LLJs on rainfall in other seasons remains unclear. In particularly, rainfall before and after the early-summer rainy season (e.g., April and July) is also significant but belongs to different types. Rainfall in April is spring rainfall before the onset of the summer monsoon, whereas July is in the postsummer rainy season in South China mainly influenced by tropical systems such as typhoons.

Figure 18 shows the relationship between LLJs and rainfall patterns in different months (April-July). Figure 19 further exhibits different large-scale background circulation in those months. In the climatological aspect, rainfall gradually increases in south China in April-June as the establishment of the subtropical high or monsoon (Figs. 18a-c and 19a-c). Rainfall reaches its maximum in June when the northwestern edge of the subtropical high is located near south China (Figs. 18c and 19c). In July, the rainfall decreases in south China but increases near the Yangtze River as the northward movement of the subtropical high (Figs. 18d and 19d).

Under the effect of the BLJ, rainfall in April is confined to the southeast coast of China near the Nanling and Wuyi Mountains (Fig. 18e), whereas rainfall in May and June rapidly increases in the south of Nanling and the YunGui Plateau (Figs. 18f,g). The 

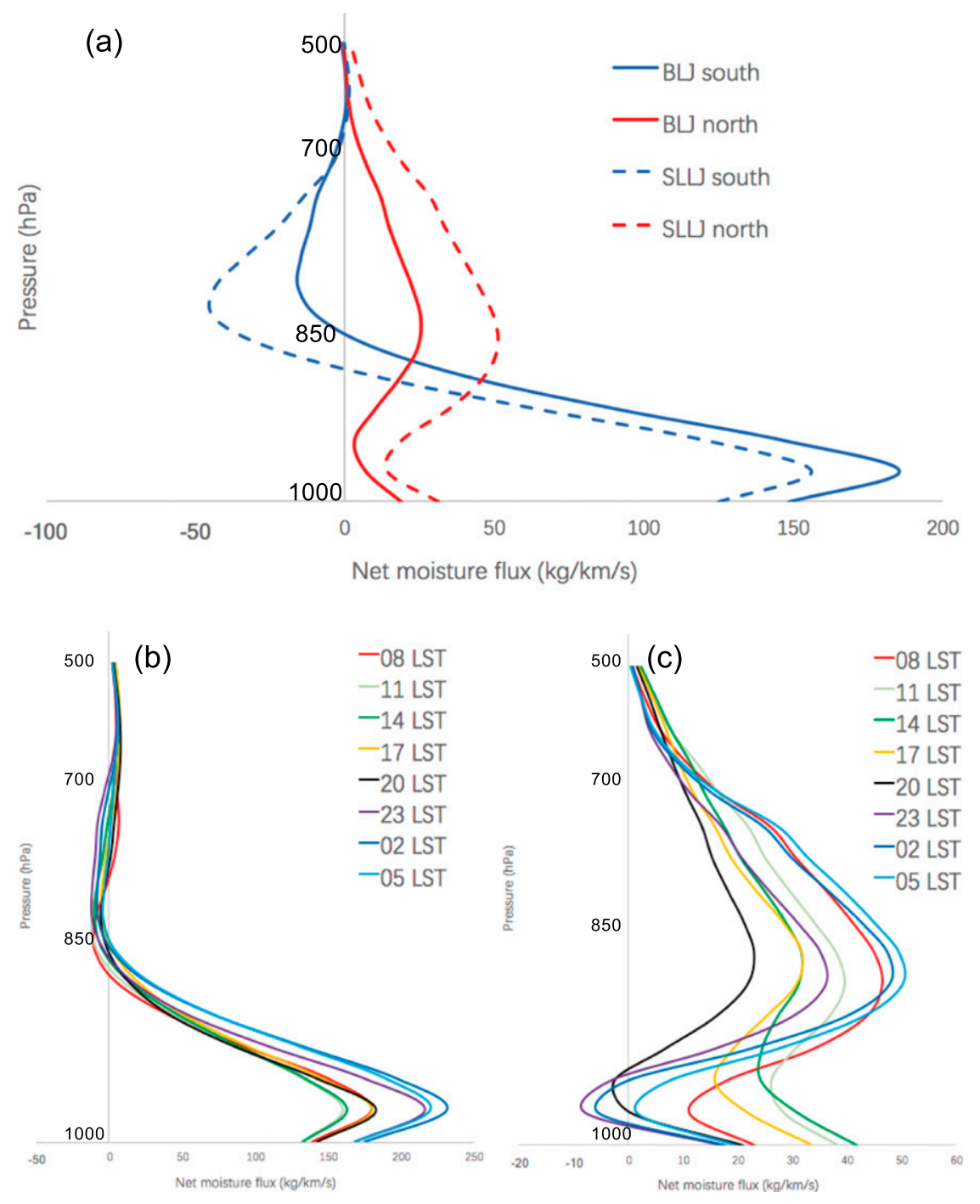

FIG. 17. (a) Vertical profiles of net moisture flux $\left(\mathrm{kg} \mathrm{km}^{-1} \mathrm{~s}^{-1}\right)$ in the north region and south region during the pure BLJ events and pure SLLJ events during the early-summer rainy season. (b),(c) Diurnal cycle of the net moisture flux $\left(\mathrm{kg} \mathrm{km}^{-1} \mathrm{~s}^{-1}\right)$ in the south region during the pure BLJ events in (b) and in the north region during the pure SLLJ events in (c).

differences of the terrain rainfall pattern in April and May-June might be attributed to different interactions between terrain and low-level flows. Since the monsoon does not onset in April, southern China is mainly influenced by a high-level westerly and low-level southeasterly wind (Fig. 19a), whereas in May-June southern China is affected by low-level southwesterly flow from the Indochina Peninsula as the monsoon onset occurs (Figs. 19b,c). Different lowlevel flow interacting with terrain might cause different moisture convergence. In July, the terrain-induced rainfall becomes weak in southern China. The heavy rainfall near the south of Taiwan may be related to typhoon rainfall (Fig. 18h).
Under the effect of SLLJ, unlike the double rainbands in June-July (Figs. 18k,1), rainfall in April only occurs near the Yangtze River but in the absence of rainfall near the coasts (Fig. 18i). This might be due to relatively weak SLLJs related to weak synoptic disturbances in the strong westerlies that cannot bring strong winds at low levels near the coasts owing to weak monsoon activities in April. The rainfall near the Yangtze River in May is not as significant as in June or July (Figs. 18j-1) because mei-yu rainfall accompanied by the SLLJ often occurs in the Yangtze River region in June and July.

Therefore, although the impact of LLJs on rainfall varies with and is regulated by seasonal changes of the large-scale circulation background, the results are 
climate
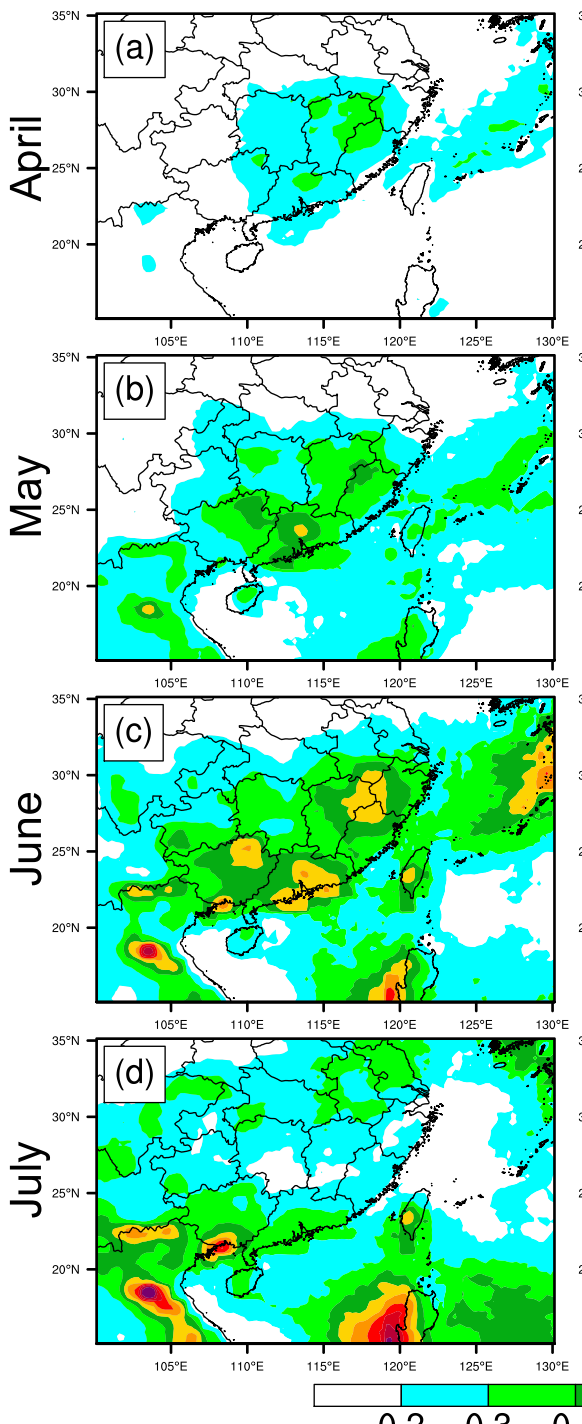

BLJ
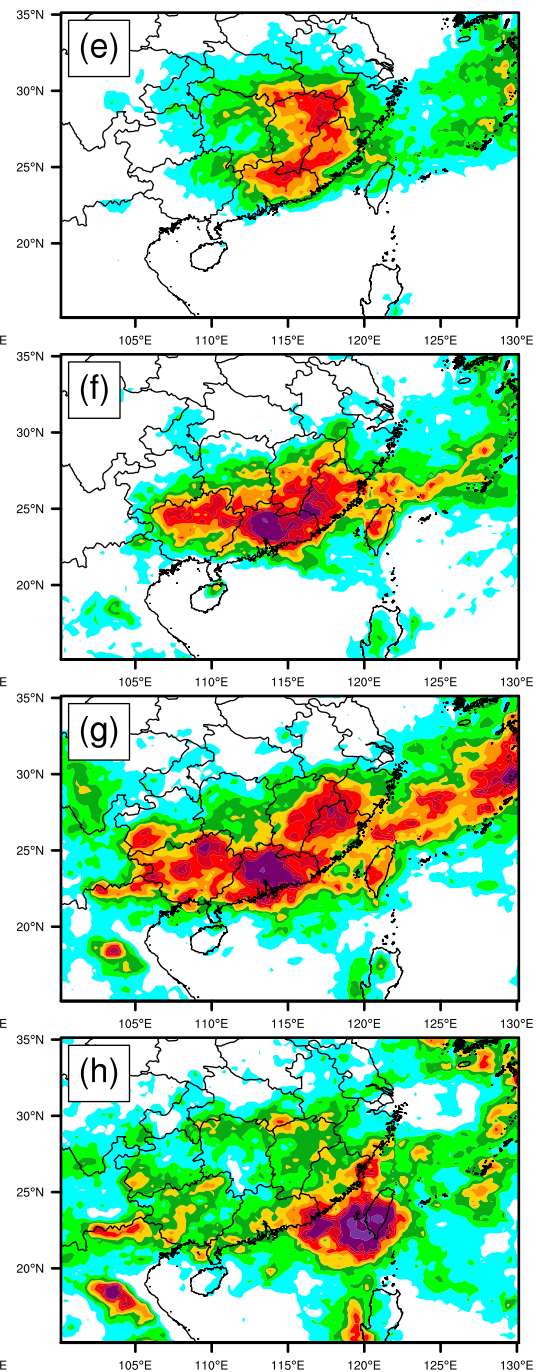
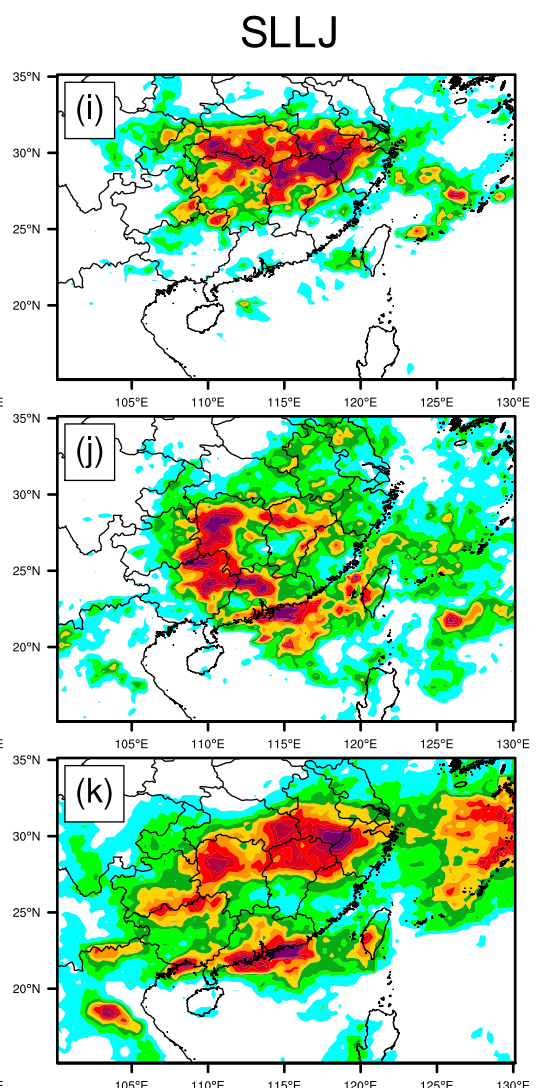

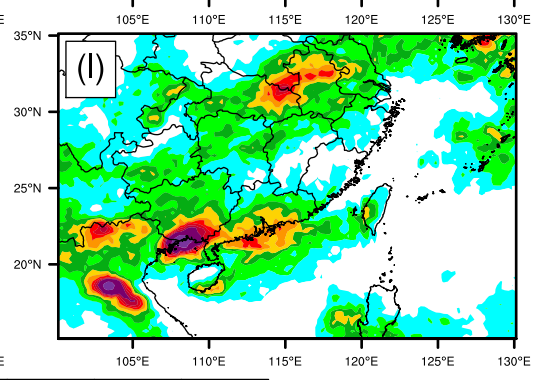

$\begin{array}{lllllllllll}0.2 & 0.3 & 0.4 & 0.5 & 0.6 & 0.7 & 0.8 & 0.9 & 1 & 1.5 & 2\end{array}$

FIG. 18. Composite of average rainfall rate $\left(\mathrm{mm} \mathrm{h}^{-1}\right)$ for (left) the climate mean, (center) pure BLJ events, and (right) pure SLLJ events during (a),(e),(i) April, (b),(f),(j) May, (c),(g),(k) June, and (d),(h),(l) July.

generally consistent with what we found in this study including terrain effect, synoptic disturbances, and moisture transportation.

\section{Summary}

In this study, we use 21 years of ERA5 reanalysis and TRMM satellite rainfall data to investigate the climatology of LLJs over southern China and their impact on rainfall. Two types of LLJs exist over southern China, consisting of boundary layer jets (BLJs) and synopticweather-related LLJs (SLLJs). To study their climatological features, LLJ events over southern China are defined and further classified into BLJ events and SLLJ events.

Both BLJ and SLLJ events exhibit obvious seasonal and interannual variation in occurrence. The BLJs frequently occur during April-June, whereas SLLJs more often occur in May-July. During the early-summer rainy season (May-June), not only does rainfall reach its annual maximum, but also both BLJs and SLLJ are relatively active over southern China and the northern region of the SCS. In the composite of BLJ events, a strong southerly jet with a maximum core at $950 \mathrm{hPa}$ occurs over the northern region of SCS. The composite of SLLJ events, however, shows a different 

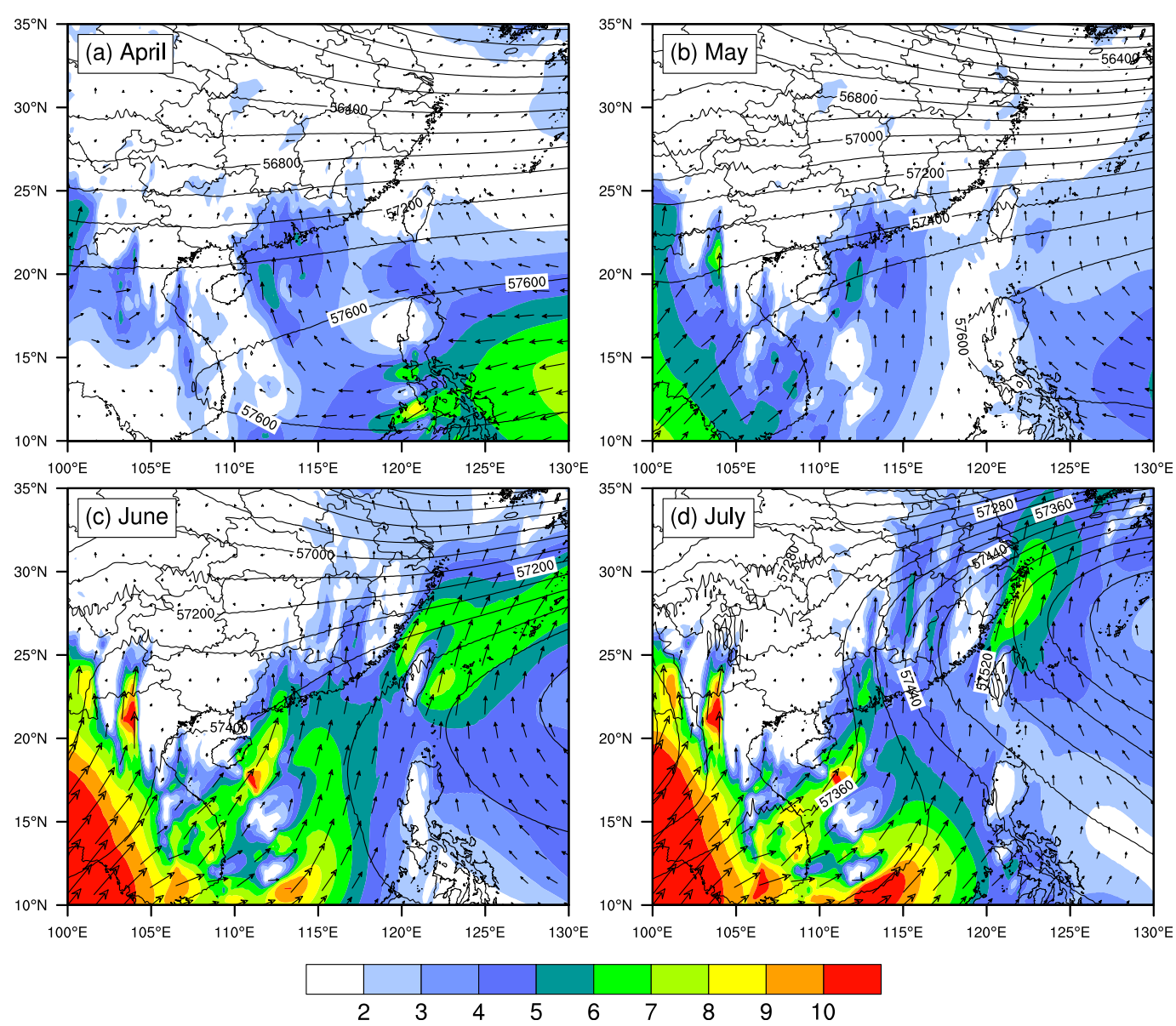

FIG. 19. Climatological composite of horizontal winds at $925 \mathrm{hPa}\left(\mathrm{m} \mathrm{s}^{-1}\right.$; shading and vectors) and geopotential $\left(\mathrm{m}^{2} \mathrm{~s}^{-2}\right)$ at $500 \mathrm{hPa}$ in (a) April, (b) May, (c) June, and (d) July.

wind pattern characterized by a southwesterly wind core at $850-700 \mathrm{hPa}$ on land. We also found that the BLJ peaks at 0200-0500 LST whereas the SLLJ peaks at 0500-0800 LST, indicating their different diurnal cycles in occurrence.

The BLJs and SLLJs can greatly influence the horizontal distribution and diurnal cycle of rainfall. During the BLJ events, rainfall mainly occurs to the south of the Nanling and Wuyi Mountains and the Yun-Gui Plateau (in the south region). In contrast, rainfall features a double-rainband pattern in the SLLJ events. Besides the coastal rainfall, rainfall can occur farther north (in the north region). From the interannual variation of rainfall and LLJ occurrences and their correlations, rainfall in the north region is found to be closely related to SLLJ occurrences, while rainfall in the south region is linked to both BLJ and SLLJ occurrences. Under the effect of BLJs and SLLJs in the diurnal cycle, the diurnal cycle of rainfall changes accordingly. More rainfall in the south region occurs at night during the BLJ events, whereas more rainfall in the north region occurs in the morning during the SLLJ events, which coincides with diurnal cycle of moisture transportation related to the LLJ.

The possible impact mechanisms of LLJ on rainfall are also explored in the present study. Topography plays a key role in modulating the distribution of rainfall through interacting with LLJs. During the BLJ events, a strong southerly boundary layer jet impinges on mountains located at the north and thus produces strong orographic lifting on the windward (south) side of mountains. However, elevated SLLJ jets can pass over the mountains, which induces upward motion and downward motion on the upside and leeside of the mountains and also cause additional lifting more north due to the leeside hydraulic jump. A double rainband distribution thus is produced in the SLLJ events. Active synoptic disturbances accompanied by SLLJs are also favorable for the rainfall in the north region. During the SLLJ events, southwesterly SLLJs form and develop on the southeast side of low pressure systems that mainly occurs in the Sichuan basin, central-east China, and the East China Sea. However, the synoptic forcing is 
relatively weak in the BLJ events. In addition to terrain effects and synoptic disturbances, moisture transportation due to LLJs is also regarded as an important factor. Moisture in the south region mainly comes from the south (ocean) and boundary layer, whereas moisture in the north region is mainly contributed from elevated layers due to the SLLJ. More moisture thus transports into the north region, resulting in more rainfall in the north region during the SLLJ events. The impact of the LLJ on rainfall can be also regulated by seasonal changes of the largescale circulation background.

In the present study, we only use reanalysis with relatively coarse resolution to study the climatology of LLJs over southern China and their impact on rainfall. In the future, to overcome the limitation due to the data resolution, we will conduct high-resolution (convection permitting) WRF simulations and dense observations to explore the LLJ activities in details. It is worth clarifying the relative importance of those impact mechanisms on rainfall that we proposed in this study using sensitivity experiments of numerical simulations. Recently, Du and Chen (2019) used high-resolution numerical simulations and found that the double LLJ pattern leads to low-level convergence due to the BLJ and midlevel divergence due to the SLLJ and thus collectively produce mesoscale lifting for convection initiation at the coast. The effect of the two types of LLJs on convection initiation and development is indeed complicated over southern China. More cases over southern China will need to be studied to clarify the detailed mesoscale effect of LLJs.

LLJs are also regarded as a bridge among multiscale forcings. The LLJ occurrences are influenced by largescale atmospheric circulation, while LLJs have a close relation with mesoscale phenomena such as convection initiation and development (e.g., Tuttle and Davis 2006; Zeng et al. 2019). Because of large-scale forcing, LLJs exhibit a distinct interannual variation as shown in the present study. Weaver and Nigam (2008) found that GPLLJ variability is linked to upper-level height patterns over the Pacific and North Atlantic Oscillation (NAO) variability in the Atlantic. The seasonal and interannual strength of GPLLJs can influence Great Plains hydroclimate via moisture fluxes (Schubert et al. 1998). It is worthwhile to study the large-scale forcing of LLJs over southern China and their impact on hydroclimate. From the perspective of mesoscale forcing, LLJs are found to produce convergence in the exit region and provide convective energy due to vertical shear and transportation of warm moist air (Augustine and Caracena 1994; Trier et al. 2006). To examine the coupling of the large-scale forcing and mesoscale forcing of LLJs, a convection-permitting regional climate model is a good option to use in the future.
Acknowledgments. This study was supported by the National Key Research and Development Program of China (Grant 2018YFC1507402), the National Natural Science Foundation of China (Grants 41875055, 41861164027, and 41575068), the Fundamental Research Funds for the Central Universities (19lgzd08), and the Young Elite Scientists Sponsorship Program by CAST (2018QNRC001).

\section{REFERENCES}

Akiyama, T., 1973: The large-scale aspects of the characteristic features of the Baiu front. Pap. Meteor. Geophys., 24, 157-188.

Astling, E. G., J. Paegle, E. Miller, and C. J. O'Brien, 1985: Boundary layer control of nocturnal convection associated with a synoptic scale system. Mon. Wea. Rev., 113, 540-552, https://doi.org/ 10.1175/1520-0493(1985)113<0540:BLCONC > 2.0.CO;2.

Augustine, J. A., and F. Caracena, 1994: Lower-tropospheric precursors to nocturnal MCS development over the central United States. Wea. Forecasting, 9, 116-135, https://doi.org/10.1175/ 1520-0434(1994)009<0116:LTPTNM>2.0.CO;2.

Banta, R. M., R. K. Newsom, J. K. Lundquist, Y. L. Pichugina, R. L. Coulter, and L. Mahrt, 2002: Nocturnal low-level jet characteristics over Kansas during CASES-99. Bound.-Layer Meteor., 105, 221-252, https://doi.org/10.1023/A:1019992330866.

Blackadar, A. K., 1957: Boundary layer wind maxima and their significance for the growth of nocturnal inversions. Bull. Amer. Meteor. Soc., 38, 283-290, https://doi.org/10.1175/ 1520-0477-38.5.283.

Bonner, W. D., 1968: Climatology of the low level jet. Mon. Wea. Rev., 96, 833-850, https://doi.org/10.1175/1520-0493(1968)096<0833: COTLLJ $>2.0 . \mathrm{CO} ; 2$.

Chen, G., T. Iwasaki, H. Qin, and W. Sha, 2014a: Evaluation of the warm-season diurnal variability over East Asia in recent reanalyses JRA-55, ERA-Interim, NCEP CFSR, and NASA MERRA. J. Climate, 27, 5517-5537, https://doi.org/10.1175/ JCLI-D-14-00005.1.

, R. Yoshida, W. Sha, T. Iwasaki, and H. Qin, 2014b: Convective instability associated with the eastward-propagating rainfall episodes over eastern China during the warm season. J. Climate, 27, 2331-2339, https://doi.org/10.1175/JCLI-D-13-00443.1.

_ - W. Sha, T. Iwasaki, and Z. Wen, 2017: Diurnal cycle of a heavy rainfall corridor over East Asia. Mon. Wea. Rev., 145, 3365-3389, https://doi.org/10.1175/MWR-D-16-0423.1.

- R. Lan, W. Zeng, H. Pan, and W. Li, 2018: Diurnal variations of rainfall in surface and satellite observations at the monsoon coast (south China). J. Climate, 31, 1703-1724, https://doi.org/ 10.1175/JCLI-D-17-0373.1.

Chen, G. T.-J., and C.-C. Yu, 1988: Study of low-level jet and extremely heavy rainfall over northern Taiwan in the mei-yu season. Mon. Wea. Rev., 116, 884-891, https://doi.org/10.1175/ 1520-0493(1988)116<0884:SOLLJA $>2.0 . C O ; 2$.

Chen, Q., 1982: The instability of the gravity-inertia wave and its relation to low-level jet and heavy rainfall.J. Meteor. Soc. Japan, 60, 1041-1057, https://doi.org/10.2151/jmsj1965.60.5_1041.

Chen, Y.-L., X. A. Chen, and Y.-X. Zhang, 1994: A diagnostic study of the low-level jet during TAMEX IOP 5. Mon. Wea. Rev., 122, 2257-2284, https://doi.org/10.1175/1520-0493(1994) 122<2257:ADSOTL > 2.0.CO;2.

Chou, L. C., C.-P. Chang, and R. T. Williams, 1990: A numerical simulation of the mei-yu front and the associated low-level jet. 
Mon. Wea. Rev., 118, 1408-1428, https://doi.org/10.1175/15200493(1990)118,1408:ANSOTM.2.0.CO;2.

Cook, K. H., and E. K. Vizy, 2010: Hydrodynamics of the Caribbean low-level jet and its relationship to precipitation. J. Climate, 23, 1477-1494, https://doi.org/10.1175/2009JCLI3210.1.

Du, Y., and R. Rotunno, 2014: A simple analytical model of the nocturnal low-level jet over the Great Plains of the United States. J. Atmos. Sci., 71, 3674-3683, https://doi.org/10.1175/ JAS-D-14-0060.1.

- and G. Chen, 2018: Heavy rainfall associated with double low-level jets over southern China. Part I: Ensemble-based analysis. Mon. Wea. Rev., 146, 3827-3844, https://doi.org/10.1175/ MWR-D-18-0101.1.

__ and __ 2019: Heavy rainfalls associated with double lowlevel jets over southern China. Part II: Convection initiation. Mon. Wea. Rev., 147, 543-565, https://doi.org/10.1175/ MWR-D-18-0102.1.

-, Q. H. Zhang, Y. Yue, and Y. M. Yang, 2012: Characteristics of low-level jets in Shanghai during the 2008-2009 warm seasons as inferred from wind profiler radar data. J. Meteor. Soc. Japan, 90, 891-903, https://doi.org/10.2151/jmsj.2012-603.

,$- \ldots$, Y. L. Chen, Y. Y. Zhao, and X. Wang, 2014: Numerical simulations of spatial distributions and diurnal variations of low-level jets in China during early summer. J. Climate, 27, 5747-5767, https://doi.org/10.1175/JCLI-D-13-00571.1.

__ , Y.-L. Chen, and Q. Zhang, 2015a: Numerical simulations of the boundary layer jet off the southeastern coast of China. Mon. Wea. Rev., 143, 1212-1231, https://doi.org/10.1175/ MWR-D-14-00348.1.

_- R. Rotunno, and Q. H. Zhang, 2015b: Analysis of WRFsimulated diurnal boundary-layer winds in eastern China using a simple 1D model. J. Atmos. Sci., 72, 714-727, https:// doi.org/10.1175/JAS-D-14-0186.1.

Fu, P., K. Zhu, K. Zhao, B. Zhou, and M. Xue, 2019: Role of the nocturnal low-level jet in the formation of the morning precipitation peak over the Dabie Mountains. Adv. Atmos. Sci., 36, 15-28, https://doi.org/10.1007/s00376-018-8095-5.

Fu, S., F. Yu, D. Wang, and R. Xia, 2013: A comparison of two kinds of eastward-moving mesoscale vortices during the meiyu period of 2010. Sci. China Earth Sci., 56, 282-300, https:// doi.org/10.1007/s11430-012-4420-5.

He, M. Y., H. B. Liu, B. Wang, and D. L. Zhang, 2016: A modeling study of a low-level jet along the Yun-Gui Plateau in south China. J. Appl. Meteor. Climatol., 55, 41-60, https://doi.org/10.1175/ JAMC-D-15-0067.1.

Higgins, R. W., Y. Yao, E. S. Yarosh, J. E. Janowiak, and K. C. Mo, 1997: Influence of the Great Plains low-level jet on summertime precipitation and moisture transport over the over the central United States. J. Climate, 10, 481-507, https://doi.org/ 10.1175/1520-0442(1997)010<0481:IOTGPL > 2.0.CO;2.

Holton, J. R., 1967: The diurnal boundary layer wind oscillation above sloping terrain. Tellus, 19, 199-205, https://doi.org/10.1111/ j.2153-3490.1967.tb01473.x.

Huang, W. R., and J. C. L. Chan, 2011: Maintenance mechanisms for the early-morning maximum summer rainfall over Southeast China. Quart. J. Roy. Meteor. Soc., 137, 959-968, https:// doi.org/10.1002/qj.815.

—_ — , and S. Y. Wang, 2010: A planetary-scale land-sea breeze circulation in East Asia and the western North Pacific. Quart. J. Roy. Meteor. Soc., 136, 1543-1553, https://doi.org/ 10.1002/qj.663.

Huffman, G. J., and Coauthors, 2007: The TRMM Multisatellite Precipitation Analysis (TMPA): Quasi-global, multiyear, combined- sensor precipitation estimates at fine scales. J. Hydrometeor., 8, 38-55, https://doi.org/10.1175/JHM560.1.

Jiang, X., N. C. Lau, I. M. Held, and J. J. Ploshay, 2007: Mechanisms of the Great Plains low-level jet as simulated in an AGCM. J. Atmos. Sci., 64, 532-547, https://doi.org/10.1175/JAS3847.1.

Li, D., H. von Storch, B. Yin, Z. Xu, J. Qi, W. Wei, and D. Guo, 2018: Low-level jets over the Bohai Sea and Yellow Sea: Climatology, variability, and the relationship with regional atmospheric circulations. J. Geophys. Res., 123, 5240-5260, https://doi.org/10.1029/2017JD027949.

Li, W., H.-C. Ren, J. Zuo, and H.-L. Ren, 2018: Early summer southern China rainfall variability and its oceanic drivers. Climate Dyn, $\mathbf{5 0}$, 4691-4705, https://doi.org/10.1007/s00382-017-3898-0.

Liu, H. B., M. Y. He, B. Wang, and Q. H. Zhang, 2014: Advances in low-level jet research and future prospects. Acta Meteor. Sin., 28, 57-85, https://doi.org/10.1007/S13351-014-3166-8.

Luo, Y., and Coauthors, 2017: The Southern China Monsoon Rainfall Experiment (SCMREX). Bull. Amer. Meteor. Soc., 98, 999-1013, https://doi.org/10.1175/BAMS-D-15-00235.1.

Matsumoto, S., K. Ninomiya, and S. Yoshizumi, 1971: Characteristic features of "Baiu" front associated with heavy rainfall. J. Meteor. Soc. Japan, 49, 267-281, https://doi.org/10.2151/ jmsj1965.49.4_267.

Miao, Y., J. Guo, S. Liu, W. Wei, G. Zhang, Y. Lin, and P. Zhai, 2018: The climatology of low-level jet in Beijing and Guangzhou, China. J. Geophys. Res., 123, 2816-2830, https://doi.org/10.1002/ 2017JD027321.

Monaghan, A. J., D. L. Rife, J. O. Pinto, C. A. Davis, and J. R. Hannan, 2010: Global precipitation extremes associated with diurnally varying low-level jets. J. Climate, 23, 5065-5084, https://doi.org/10.1175/2010JCLI3515.1.

Rasmussen, K. L., and R. A. Houze, 2016: Convective initiation near the Andes in subtropical South America. Mon. Wea. Rev., 144, 2351-2374, https://doi.org/10.1175/MWR-D-15-0058.1.

Rife, D. L., J. O. Pinto, A. J. Monaghan, C. A. Davis, and J. R. Hannan, 2010: Global distribution and characteristics of diurnally varying low-level jets. J. Climate, 23, 5041-5064, https://doi.org/ 10.1175/2010JCLI3514.1.

Rotunno, R., and G. H. Bryan, 2018: Numerical simulations of two-layer flow past topography. Part I: The leeside hydraulic jump. J. Atmos. Sci., 75, 1231-1241, https://doi.org/ 10.1175/JAS-D-17-0306.1.

Schubert, S. D., H. M. Helfand, C.-Y. Wu, and W. Min, 1998: Subseasonal variations in warm-season moisture transport and precipitation over the central and eastern United States. J. Climate, 11, 2530-2555, https://doi.org/10.1175/1520-0442(1998)011<2530: SVIWSM $>2.0 . \mathrm{CO} ; 2$.

Shapiro, A., and E. Fedorovich, 2009: Nocturnal low-level jet over a shallow slope. Acta Geophys. 57, 950-980, https://doi.org/ 10.2478/s11600-009-0026-5.

,-- , and S. Rahimi, 2016: A unified theory for the Great Plains nocturnal low-level jet. J. Atmos. Sci., 73, 3037-3057, https://doi.org/10.1175/JAS-D-15-0307.1.

Shen, Y., A. Xiong, Y. Wang, and P. Xie, 2010: Performance of highresolution satellite precipitation products over China. J. Geophys. Res., 115, D02114, https://doi.org/10.1029/2009JD012097.

Shu, Z. R., Q. S. Li, Y. C. He, and P. W. Chan, 2018: Investigation of low-level jet characteristics based on wind profiler observations. J. Wind Eng. Ind. Aerodyn., 174, 369-381, https:// doi.org/10.1016/j.jweia.2018.01.035.

Stensrud, D. J., 1996: Importance of low-level jets to climate: A review. J. Climate, 9, 1698-1711, https://doi.org/10.1175/1520-0442(1996) 009<1698:IOLLJT>2.0.CO;2. 
Sun, J., and F. Zhang, 2012: Impacts of mountain-plains solenoid on diurnal variations of rainfalls along the mei-yu front over the East China plains. Mon. Wea. Rev., 140, 379-397, https:// doi.org/10.1175/MWR-D-11-00041.1.

Tao, S., and L. Chen, 1987: A review of recent research on the East Asian summer monsoon in China. Monsoon Meteorology, C.-P. Chang and T. N. Krishnamurti, Eds., Oxford University, 60-92.

Ting, M., and H. Wang, 2006: The role of the North American topography on the maintenance of the Great Plains summer low-level jet. J. Atmos. Sci., 63, 1056-1068, https://doi.org/ 10.1175/JAS3664.1.

Trier, S. B., and D. B. Parsons, 1993: Evolution of environmental conditions preceding the development of a nocturnal mesoscale convective complex. Mon. Wea. Rev., 121, 1078-1098, https:// doi.org/10.1175/1520-0493(1993)121<1078:EOECPT>2.0.CO;2.

, C. A. Davis, D. A. Ahijevych, M. L. Weisman, and G. H. Bryan, 2006: Mechanisms supporting long-lived episodes of propagating nocturnal convection within a 7-day WRF model simulation. J. Atmos. Sci., 63, 2437-2461, https://doi.org/10.1175/JAS3768.1.

Tu, C., Y. Chen, P. Lin, and Y. Du, 2019: Characteristics of the marine boundary layer jet over the South China Sea during the early summer rainy season of Taiwan. Mon. Wea. Rev., 147, 457-475, https://doi.org/10.1175/MWR-D-18-0230.1.

Tuttle, J., and C. A. Davis, 2006: Corridors of warm-season precipitation in the central United States. Mon. Wea. Rev., 134, 2297-2317, https://doi.org/10.1175/MWR3188.1.

Uccellini, L. W., 1980: On the role of upper tropospheric jet streaks and leeside cyclogenesis in the development of low-level jet in the Great Plains. Mon. Wea. Rev., 108, 1689-1696, https://doi.org/ 10.1175/1520-0493(1980)108<1689:OTROUT>2.0.CO;2.

- , and D. R. Johnson, 1979: The coupling of upper and lower tropospheric jet streaks and implications for the development of severe convective storms. Mon. Wea. Rev., 107, 682-703, https:// doi.org/10.1175/1520-0493(1979)107<0682:TCOUAL >2.0.CO;2.

Weaver, S. J., and S. Nigam, 2008: Variability of the Great Plains lowlevel jet: Large-scale circulation context and hydroclimate impacts. J. Climate, 21, 1532-1551, https://doi.org/10.1175/2007JCLI1586.1.

Whiteman, C. D., X. Bian, and S. Zhong, 1997: Low-level jet climatology from enhanced rawinsonde observations at a site in the southern Great Plains. J. Appl. Meteor., 36, 1363-1376, https://doi.org/10.1175/1520-0450(1997)036<1363:LLJCFE> 2.0.CO;2.

Xue, M., X. Luo, K. Zhu, Z. Sun, and J. Fei, 2018: The controlling role of boundary layer inertial oscillations in meiyu frontal precipitation and its diurnal cycles over China. J. Geophys. Res. Atmos., 123, 5090-5115, https://doi.org/10.1029/2018JD028368.

Zeng, W., G. Chen, Y. Du, and Z. Wen, 2019: Diurnal variations of low-level winds and rainfall response to large-scale circulations during a heavy rainfall event. Mon. Wea. Rev., 147, 39814004, https://doi.org/10.1175/MWR-D-19-0131.1.

Zhang, F., Q. Zhang, Y. Du, and H. Kong, 2018: Characteristics of coastal low-level jets in the Bohai Sea, China, during the early warm season. J. Geophys. Res. Atmos., 123, 13763-13774, https:// doi.org/10.1029/2018jd029242.

Zhang, Y., M. Xue, K. Zhu, and B. Zhou, 2019: What is the main cause of diurnal variation and nocturnal peak of summer precipitation in Sichuan Basin, China? The key role of boundary layer low-level jet inertial oscillations. J. Geophys. Res., 124, 2643-2664, https://doi.org/10.1029/2018JD029834.

Zhou, T., R. Yu, H. Chen, A. Dai, and Y. Pan, 2008: Summer precipitation frequency, intensity, and diurnal cycle over China: A comparison of satellite data with rain gauge observations. J. Climate, 21, 3997-4010, https://doi.org/10.1175/ 2008JCLI2028.1. 